\title{
Recent Progress in Fabrications and Applications of Heating-Induced Long Period Fiber Gratings
}

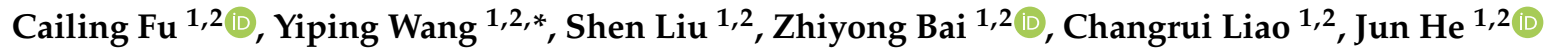 \\ and Ying Wang ${ }^{1,2}$ \\ 1 Guangdong and Hong Kong Joint Research Centre for Optical Fibre Sensors, College of Physics and \\ Optoelectronic Engineering, Shenzhen University, Shenzhen 518060, China; fucailing89@163.com (C.F.); \\ shenliu@szu.edu.cn (S.L.); baizhiyong@szu.edu.cn (Z.B.); cliao@szu.edu.cn (C.L.); hejun07@szu.edu.cn (J.H.); \\ yingwang@szu.edu.cn (Y.W.) \\ 2 Key Laboratory of Optoelectronic Devices and Systems of Ministry of Education and Guangdong Province, \\ Shenzhen University, Shenzhen 518060, China \\ * Correspondence: ypwang@szu.edu.cn; Tel.: +86-755-2606-6281
}

Received: 20 August 2019; Accepted: 2 October 2019; Published: 15 October 2019

check for updates

\begin{abstract}
This paper presents a review of our work concerning the recent progress in fabrications and applications of heating-induced long period fiber gratings (LPFGs). Firstly, three kinds of heating fabrication techniques based on $\mathrm{CO}_{2}$ laser, hydrogen-oxygen flame and arc discharge are demonstrated to fabricate LPFGs, i.e., standard LPFGs (SLPFGs) and helical LPFGs (HLPFGs), in different types of optical fibers such as conventional fibers, photonic crystal fibers, and photonic bandgap fibers. Secondly, the all-fiber orbital angular momentum (OAM) mode converters based on heating-induced SLPFGs and HLPFGs in different types of fibers are studied to increase the transmission capacity. Finally, the heating-induced SLPFGs and HLPFGs are investigated to develop various LPFG-based strain, pressure, torsion and biochemical sensors.
\end{abstract}

Keywords: long period fiber gratings; fiber optic sensors; orbital angular momentum; mode converter

\section{Introduction}

The optical fiber gratings play a vital role in the field of optical communications and fiber optical sensing. In-fiber gratings are divided into two types, i.e., fiber Bragg gratings (FBGs) with periodicities of the order of the optical wavelength [1-4] and long period fiber gratings (LPFGs) with periodicities of several hundred wavelengths [5-7]. The working principle of the LPFG is the coupling between the forward-propagating core mode and several cladding modes co-propagating in the same direction. Vengsarkar et al. wrote the first standard LPFG (SLPFG) with periodic refractive index change in the conventional glass fiber core using an ultraviolet (UV) laser radiation in 1996 [8]. Compared with SLPFG, helical LPFG (HLPFG) refers to a fiber where there exists a periodical helical structure such as a screw index-modulation along the fiber axis [9-22]. A HLPFG with double helix symmetry was firstly produced by twisting glass optical fiber with a noncircular core cross section as it passed through a miniature oven [9]. Following this, the fabrications and applications of LPFGs, including SLPFGs and HLPGs, were rapidly developed. Various methods to fabricate the LPFG, such as $\mathrm{CO}_{2}$ laser [23-32], arc discharge [33-38], hydrogen-oxygen flame heating [13-17,22], femtosecond laser [39,40], mechanical micro-bend [41,42], etched corrugations [43,44], and ion beam implantation [45], have been proposed and demonstrated. One of the key steps of fabricating the LPFG is to introduce periodic refractive index modulation in the fiber. Among above-mentioned fabrication techniques, $\mathrm{CO}_{2}$ laser, arc discharge, and hydrogen-oxygen flame all heat the fiber into a fused status, then the periodic refractive index modulation in the fiber is reserved due to the possible mechanisms, i.e., residual stress relaxation, 
physical deformation, and structural changes. Various heating-induced LPFGs in conventional fiber $[12,13,22,28,35,46,47]$, photonic crystal fiber (PCF) [14-16,29,48], and photonic bandgap fiber (PBF) $[27,30,31]$ could then be successfully written. LPFG-based devices have recently attracted great attention and found versatile applications, such as in all-fiber orbital angular momentum (OAM) mode converters $[11,13,14,17,49-56]$, and strain $[48,57-64]$, pressure $[16,29,30,65,66]$, torsion $[16,19,38,46]$ and biochemical sensors [67-73].

This paper presents a review of our recent work concerning the recent progress in fabrications and applications of heating-induced LPFGs. The heating fabrication techniques, i.e., $\mathrm{CO}_{2}$ laser, arc discharge, and hydrogen-oxygen flame heating, for writing SLPFGs and LPFGs in conventional glass fiber, PCF and PBF are presented in Section 2. Then the in-fiber orbital angular momentum (OAM) mode converters based on SLPFGs and HLPFGs are described in Section 3. Subsequently, the strain, pressure, torsion and biochemical sensors using the heating-induced LPFGs are outlined in Sections 4-7, respectively. Finally, the review paper is concluded.

\section{Fabrications}

Various fabrication techniques have been demonstrated and improved to fabricate high-quality SLPFGs and HLPFGs in different types of optical fibers. Compared with SLPFG, HLPFG refers to a fiber where there exists a periodical helical structure such as a screw index-modulation along the fiber axis [9-12,47]. The heating fabrication techniques, i.e., $\mathrm{CO}_{2}$ laser, arc discharge, and hydrogen-oxygen flame as the heat source, could be used to write SLPFGs and HLPFGs in conventional glass fiber, PCF, and PBF.

\section{1. $\mathrm{CO}_{2}$ Laser Heating Techniques}

Since Davis et al. reported the first $\mathrm{CO}_{2}$-laser-induced SLPFG in a conventional glass fiber [6,7], various $\mathrm{CO}_{2}$ laser heating techniques have been demonstrated and improved to obtain high-quality SLPFGs. A typical point-to-point $\mathrm{CO}_{2}$-laser irradiation technique is periodically moving the fiber along its axis direction. Rao et al. demonstrated a $\mathrm{CO}_{2}$-laser fabrication system in which an industrial two-dimensional optical scanner was employed to write high-quality SLPFGs with nearly zero insertion loss [23-25]. However, a lower power stability of the industrial $\mathrm{CO}_{2}$ laser leads to a poor reproducibility of the fabricated SLPFGs.
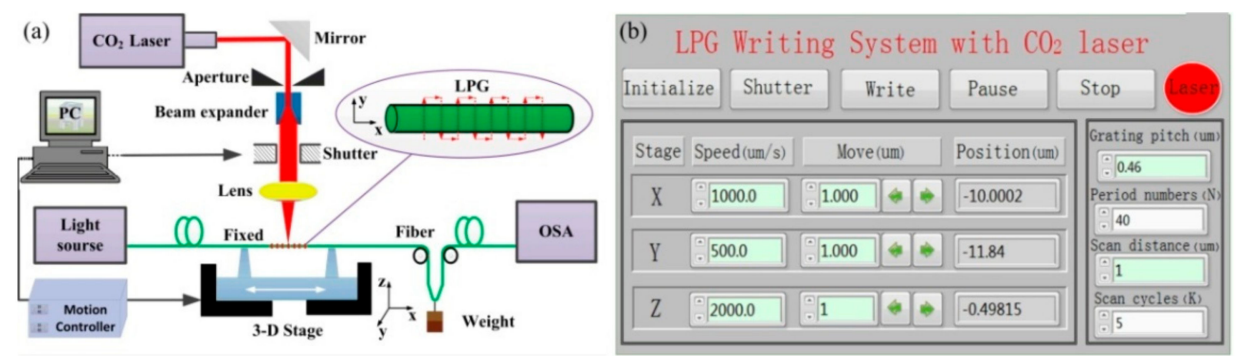

Figure 1. (a) Experimental setup and (b) operation interface of the standard long period fiber grating (SLPFG) fabrication system by using $\mathrm{CO}_{2}$ laser heating technique [28].

As shown in Figure 1, the authors demonstrated a SLPFG fabrication system, consisting of an industrial $\mathrm{CO}_{2}$ laser (SYNRAD 48-1), an electric shutter, a ZNSE PO/CX lens, a four-times beam expander, and a three-dimensional stage, based on an improved two-dimensional scanning technique by use of a focused $\mathrm{CO}_{2}$ laser $[28,29,31,32,48,74]$. An improved stability and reproducibility of the fabrication system is attributed to the employed closed loop control system. The SLPFG fabricating process could be started, paused and stopped randomly by using the buttons "Write", "Pause", and "Stop", respectively [28]. As shown in Figure 1a, firstly, one end of a fiber is fixed by a dual-arm fiber holder on the three-dimensional motorized stage and another end is fixed by a small weight, providing a constant pre-strain to enhance the efficiency of inscribing SLPFGs. Secondly, the fiber is heated across 
the " $\mathrm{Y}$ " direction using the $\mathrm{CO}_{2}$ laser, thus creating the first period. Thirdly, the stage is shifted along the " $X$ " direction with the set grating pitch $(\Lambda)$, then repeating step 2 . These steps are repeated until the last period, i.e., repeating $\mathrm{N}$ times. Finally, the above-mentioned process is repeated for $\mathrm{K}$ cycles until a desired SLPFG is created.

In addition, the HLPFG fabrication systems by use of $\mathrm{CO}_{2}$ laser heating technique are also demonstrated. As shown in Figure 2a, the experimental setup for fabricating the HLPFG is composed of a rotation motor, a translation stage, two fiber holders, a focal lens, and a guider by means of $\mathrm{CO}_{2}$ laser [10]. While the fiber is rotated by use of the rotation motor, the actuator translates the fiber along its axis. The helical refractive index modulation is induced by $\mathrm{CO}_{2}$ laser beam irradiation onto a fiber while it rotates and moves continuously along the optical fiber axis. The HLPFG showed a similar transmission spectrum to that of a SLPFG [10].
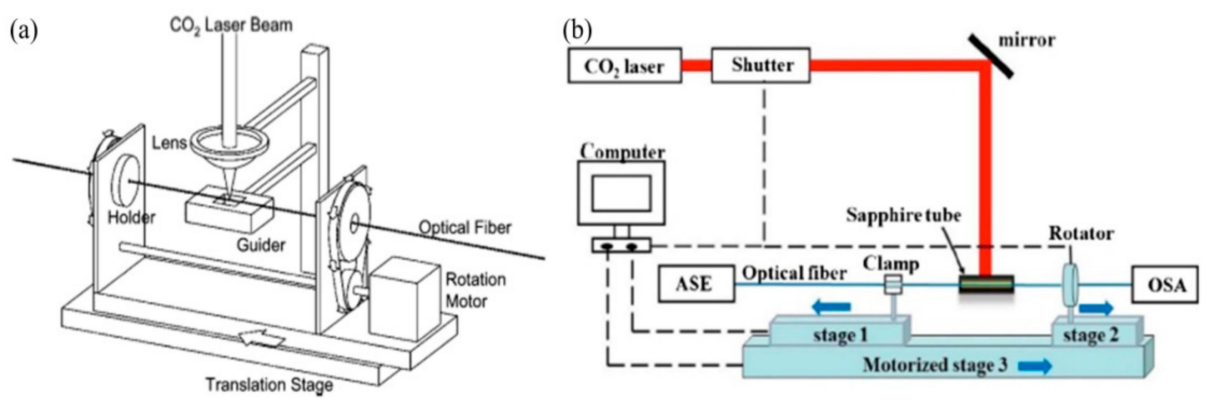

Figure 2. (a,b) Experimental setups for fabricating the helical LPFG (HLPFG) by use of $\mathrm{CO}_{2}$ laser $[10,11]$.

The large power fluctuations of the $\mathrm{CO}_{2}$ laser led to the poor reproducibility of the HLPFGs. To solve this problem, Wang et al. added a sapphire tube to heat the fiber uniformly [11]. As shown in Figure $2 \mathrm{~b}, \mathrm{CO}_{2}$ laser heating technique is experimentally improved by using the sapphire tube to take place of the focal lens. The sapphire tube is used to provide a stable and constant temperature inside to heat the fiber to the fused status. The mechanism of the formed HLPFGs could be explained as the inherent core-cladding eccentricity during fiber drawing [11].

As shown in Figure 3a, a commercial fusion splicer (Fujikura, LAZERMaster LZM-100) using the $\mathrm{CO}_{2}$ laser as a heat source was developed to fabricate HLPFG. The $\mathrm{CO}_{2}$ laser incorporated with a real-time feedback system was divided into two beams to heat the fiber in two contrary directions [12]. Compared with Figure $2 b$, a smaller beam size of the $\mathrm{CO}_{2}$ laser would ensure a smaller fused area to be twisted with the rotation motor correctly, increasing the accuracy. As shown in Figure 3b, Li et al. designed a double-side $\mathrm{CO}_{2}$ laser fabrication system. Firstly, the fiber was twisted with $180^{\circ}$ in the opposite directions by the two rotator motors. Then, the double-side $\mathrm{CO}_{2}$ laser was employed to irradiate the fiber [47].
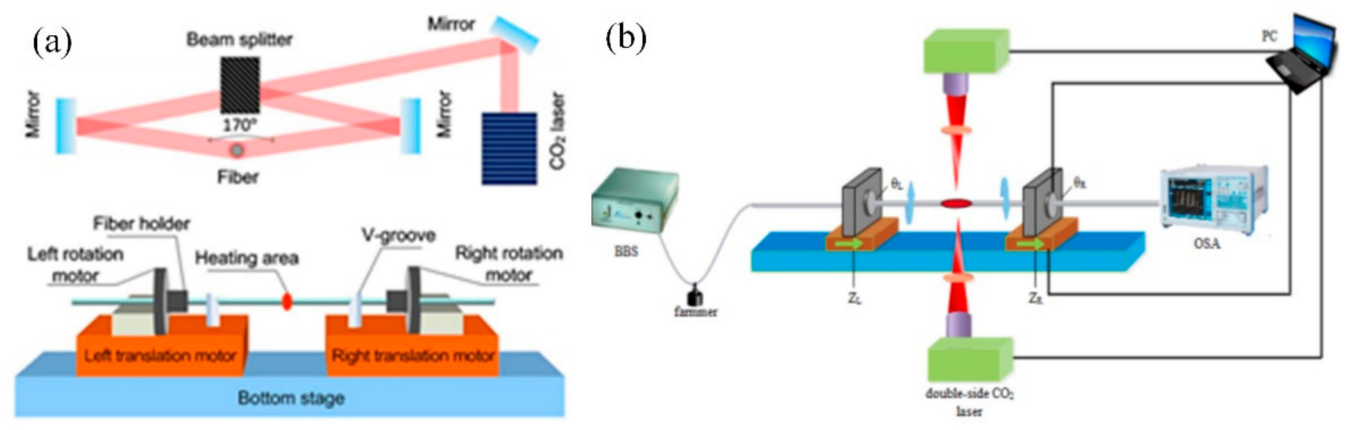

Figure 3. (a,b) Schematic diagrams for fabricating HLPFG using double-side $\mathrm{CO}_{2}$ laser [12,47].

Using these inscribing systems based on $\mathrm{CO}_{2}$ laser, various types of heating-induced SLPFG and HLPFG in conventional glass fiber, PCF and PBF are fabricated. 


\subsubsection{LPFGs in Conventional Fiber}

As shown in Figure 4a, one high-quality heating-induced SLPFG in a standard single mode fiber (SMF) with a dip attenuation of $-35.66 \mathrm{~dB}$ and a low insertion loss of less than $0.3 \mathrm{~dB}$ was achieved by using the experimental setup in Figure 1 [28]. During the fabrication, the resonant wavelength shifted toward the shorter wavelength, and the attenuation increased with the increase of K. No obvious deformation on the surface was observed, and possible mechanisms for refractive index modulation in the SLPFGs are the glass densification and residual stress relaxation [74].
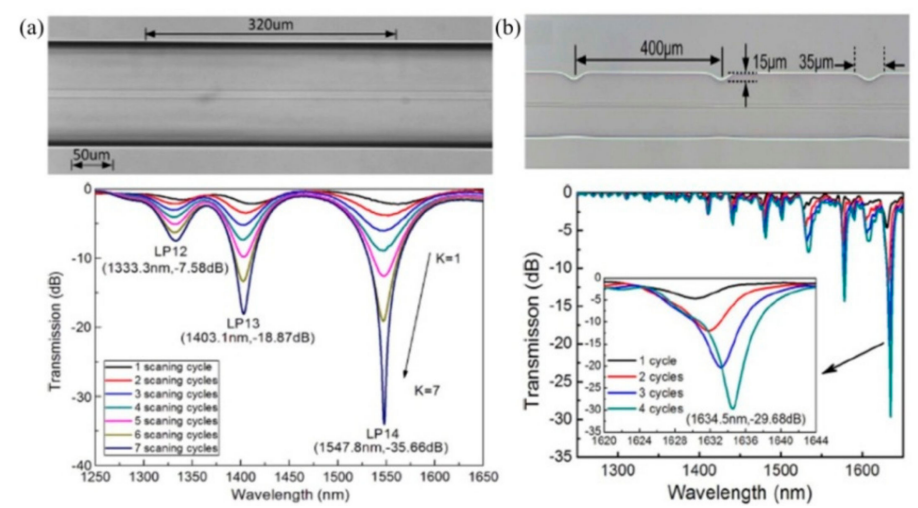

Figure 4. Microscope image and transmission spectrum of the $\mathrm{CO}_{2}$-laser-inscribed SLPFGs in (a) single mode fiber (SMF) [28] and (b) thin core fiber (TCF) [32].

Then, an asymmetrical SLPFG was also inscribed in a thin core fiber (TCF) [32]. A local high temperature resulting from the repeated scanning of the $\mathrm{CO}_{2}$ laser created a local high temperature in the TCF, which led to the melting and gasification of $\mathrm{SiO}_{2}$ on the fiber surface. Consequently, periodic grooves with a notch depth and notch width of 15 and $35 \mu \mathrm{m}$, respectively, were carved on one side of the TCF, as shown in Figure $4 \mathrm{~b}$. The resonant wavelength shifted toward a longer wavelength while $\mathrm{K}$ increased, which is opposite to that of the SLPFGs in SMF [28]. Such heating-induced SLPFG exhibited a narrowed 3-dB bandwidth and high polarization-dependent loss of $8.7 \mathrm{~nm}$ and $20 \mathrm{~dB}$. The large polarization-dependent loss resulted from the single-side exposure of the $\mathrm{CO}_{2}$ laser. Moreover, the author also successfully inscribed a SLPFG in a four-mode fiber (FMF). Such a SLPFG could be used as a OAM mode converter, i.e., generating $\mathrm{OAM}_{ \pm 1}$ modes [49].

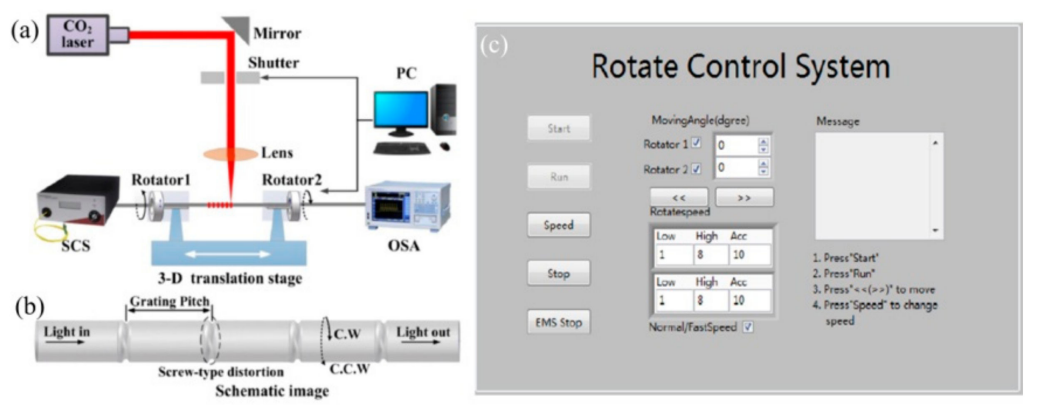

Figure 5. (a) Schematic diagram for fabricating pre-twisted LPFG by use of CO2 laser; (b) microscope image of a right-helix pre-twisted LPFG with permanent screw-type deformation; (c) operation interface of the pre-twisted LPFG fabrication system [46].

A new type of $\mathrm{CO}_{2}$-laser-induced LPFG with a helical structure has been proposed and demonstrated. The authors fabricated a pre-twisted LPFG with permanent screw-type deformations by periodically twisting a SMF under $\mathrm{CO}_{2}$ laser irradiation [46]. The fabrication system for inscribing a pre-twisted LPFG was built by improving the experimental setup in [28]. As shown in Figure 5a, rotator1 and rotator2 were employed to simultaneously twist the fused SMF in opposite directions 
to form the screw-type deformations in the fiber. As show in Figure $5 c$, a LabVIEW program was completed to control the rotation angle $(\beta)$, velocity $(v)$ and direction, where the pre-twist of the LPFG is calculated using the equation $\alpha=2 \beta / \mathrm{L}$. The schematic of the pre-twisted LPFG is illustrated in Figure $5 b$, which could be used as a torsion sensor with enhanced sensitivity.

Moreover, Oh et al. presented an optical torque sensor based on a HLPFG in SMF by the experimental setup in Figure 2a [10]. Subsequently, three kinds of thinned HLPFGs with smaller diameters were also fabricated by the improved experimental setup in Figure 2b [11], and then a flat-top band-rejection filter was obtained by successively cascading two HLPFGs with opposite helicities [75].

In addition to the HLPFGs in SMF, the HLPFG in two-mode fiber (TMF) has also been fabricated using $\mathrm{CO}_{2}$ laser [76]. Shen et al. have demonstrated a HLPG in a multi-core fiber by means of combing the $\mathrm{CO}_{2}$ laser heating technology and twist process [77]. The HLPFG in multi-core fiber shows great potential as a twist sensor and can be applied for measuring twist directions. The HLPFG inscribed in polarization-maintaining fiber by $\mathrm{CO}_{2}$ laser heating technique has been investigated experimentally. The achieved HLPFG could be used as a PDL compensator owing to a high polarization extinction ratio of more than $30 \mathrm{~dB}$ at the resonant wavelength [78]. HLPFGs have recently drawn considerable attention in these applications, such as torsion sensors [16], band-rejection filter [75,79] and conversion of orbital angular momentum (OAM) modes [13-15,17,18,20], due to their inherent helical structure and low polarization-dependent loss. This section reviews these heating fabrication techniques.

\subsubsection{LPFGs in PCF}

Solid-core PCFs have attracted great attention owing to their special microstructures in the cladding and optical properties. Since Eggleton et al. reported the grating in a photosensitive PCF with a Ge-doped core in 1999 [80], various LPFGs in different types of PCFs have been reported [81]. Kakarantzas et al. fabricated a structural SLPFG in pure-silica solid-core PCF via $\mathrm{CO}_{2}$ laser. The periodic hole-size perturbation facing the $\mathrm{CO}_{2}$ laser induced the core mode coupling to the cladding mode [82].

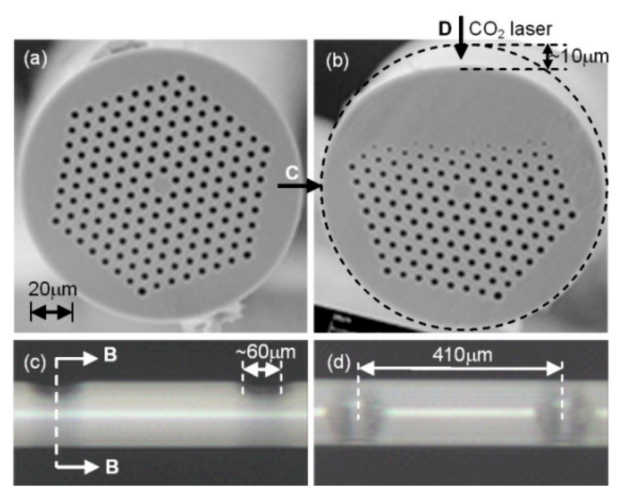

Figure 6. Scanning electron micrographs of the employed photonic crystal fiber (PCF) (a) before (b) after $\mathrm{CO}_{2}$ laser irradiation; (c,d) micrographs of the obtained asymmetrical SLPFG with periodic grooves [57].

As shown in Figure 6, an asymmetrical SLPFG with periodic grooves was written in a PCF by use of a focused $\mathrm{CO}_{2}$ laser beam $[57,74]$. The periodic refractive index modulations in the fiber are induced by the periodic grooves with a depth and width of 15 and $50 \mu \mathrm{m}$, respectively, as shown in Figure 6b, thus creating a heating-induced SLPFG in the PCF. This asymmetrical SLPFG has unique optical properties, e.g., high strain sensitivity, low temperature sensitivity and high polarization dependence. Then an inflated SLPFG (I-SLPFG) in the PCF, as shown in Figure 7, was fabricated by means of periodically inflating the air holes, i.e., a pressure-assisted $\mathrm{CO}_{2}$ laser heating technique [48]. When the air pressure with a value of $\sim 1.5 \mathrm{MPa}$ in the PCF was stable, then the PCF was periodically heated. As a result, the periodic inflations of the air holes are caused by the $\mathrm{CO}_{2}$-laser-induced high temperature 
and high-pressure air, thus introducing periodic refractive index modulation in the PCF. Such periodic inflations enhanced the strain [48] and pressure sensitivity [29].
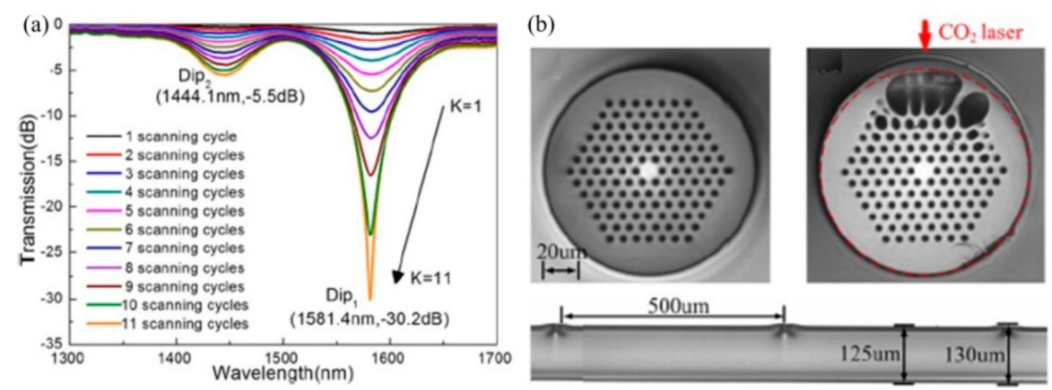

Figure 7. (a) Transmission spectrum evolution of a $\mathrm{CO}_{2}$-laser-heated inflated SLPFG (I-SLPFG) in a solid-core PCF while the number of scanning cycles increases; (b) microscope images of the I-SLPFG with periodic inflations $[29,48]$.

In addition to these asymmetrical SLPFGs, the symmetrical SLPFGs in PCF were also fabricated by $\mathrm{CO}_{2}$ laser irradiation by using a $120^{\circ}$ gold-coated reflecting silicon mirror [26]. Furthermore, Zhu et al. reported an extremely short LPFG with eight periods and a 2.8-mm length in a PCF via a point-to-point $\mathrm{CO}_{2}$ laser technique, where obvious physical deformation in the fiber was observed [83]. In contrast, another strain-insensitive and high-temperature SLPFG without geometrical deformation and elongation of the PCF was fabricated by periodic mechanically residual stress due to $\mathrm{CO}_{2}$ laser heating [84]. The $\mathrm{CO}_{2}$ laser heating technique could also be used to fabricate SLPFGs in polarization-maintaining PCF. Results show that the irradiation orientation of the $\mathrm{CO}_{2}$ laser beam strongly influences the writing efficiency. The highest efficiency was obtained when the irradiation orientation is along the slow axis of the fiber [85].

Compared with SLPFG in PCF, a helical PCF, i.e., a so-called HLPFG in PCF, with a series of helices for the air-hole in the cladding, was repeated by the twisted period, as illustrated in Figure 8b [18]. The periodic helical microstructure of the HLPFG in the PCF creates a series of unusual and fascinating effects. In an un-twisted PCF, the air-holes in the cladding move along the fiber axis, as illustrated in Figure 8a.To date, various methods were proposed and demonstrated to introduce the helical structure in the fiber by applying external mechanical torsion [86], spinning the preform during the fiber drawing [87] and using the heat-processing methods.
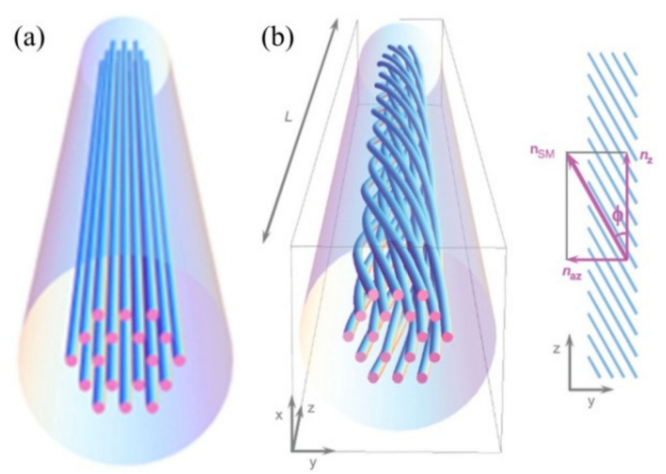

Figure 8. Schematics of (a) a solid-core PCF and (b) HLPFG in PCF. The blue tubes are the air-hole channels in the cladding area [18].

As shown in Figure 9a, one end of the PCF is fixed by the fiber holder, another end is mounted at the center of a motorized rotator. As shown in Figure 8b, light in the cladding, i.e., the air-hole of the PCF, is constrained to follow a helical path due to the helical lattice of air holes in the cladding. Then, the discrete OAM resonance resulting from the azimuthal momentum could be generated, 
i.e., the resonance dips in the transmission spectrum [28]. The circular birefringence in the spectral regions without OAM was studied [21]. A continuous permanent twist rate was induced in the three-bladed Y-shaped core PCF by using a $\mathrm{CO}_{2}$ laser as heat source [20]. The twist period was a few millimeters or less, and the HLPFG have been shown to support helical Bolch waves and exhibit OAM birefringence. HLPFGs in the PCF have recently drawn considerable interest such as generation of the OAM modes, formation of the HLPFG $[9,10]$, suppression of the high-order mode in lasers [88], and the sensors $[19,89]$.

(a)

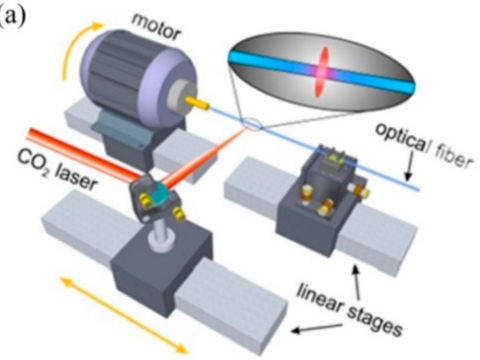

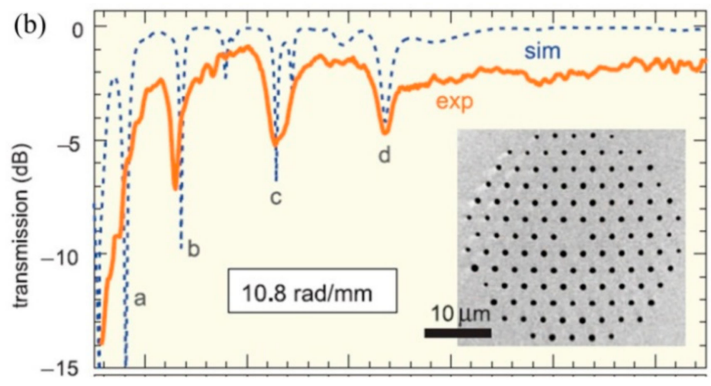

Figure 9. (a) Experimental setup for fabricating the HLPFG in PCF by use of $\mathrm{CO}_{2}$ laser; (b) the simulated and measured transmission spectrum of HLPFG in PCF [18].

\subsubsection{LPFGs in PBF}

PBF, including air-core PBF, fluid-filled PBF and all-solid PBF, confines light in a low refraction index core by photonic bandgap effect of the cladding. High order resonances between fundamental core mode and cladding super modes of LPFGs in all-solid PBF are demonstrated through a point-to-point side illumination process using $\mathrm{CO}_{2}$ laser [90]. Air-core PBFs have potential to overcome some of the fundamental limitations of solid fibers, promising, for example, reduced transmission loss, lower nonlinearity, higher damage thresholds and lower latency [91].

Wang et al. reported a SLPFG in an air-core PBF using a similar experimental setup in [25], i.e., a focused $\mathrm{CO}_{2}$ laser beam, to periodically deform/perturb air holes along the fiber axis [27]. As shown in Figure 10a, the outer rings of air holes facing the $\mathrm{CO}_{2}$ laser are largely deformed, which is induced by the ablation of glass on the fiber surface and the partial or complete collapse of air holes in the cladding due to the $\mathrm{CO}_{2}$-laser-induced local high temperature. The dominant factor of the formed SLPFG in air-core fiber is the periodic geometrical deformations that causes resonant mode coupling.

The author further fabricated SLPFGs in air-core PBF using the improved experimental setup in [28], i.e., an improved two-dimensional scanning technique by use of a $\mathrm{CO}_{2}$ laser beam [30]. Compared with 50 scanning cycles [27], as shown in Figure 10b, a high coupling efficiency of two resonant dips, i.e., $\mathrm{Dip}_{1}$, Dip ${ }_{2}$, could be up to $-10.61 \mathrm{~dB}$ and $-9.15 \mathrm{~dB}$, respectively, with only six scanning cycles, indicating that the writing efficiency was greatly improved. The relatively low power fluctuation, i.e., a power stability of $\pm 2 \%$, improves the uniformity of the periodic collapse along the fiber axis, enhancing the mode coupling. Hence, a SLPFG in air-core PBF with relatively large depth at the resonant dip is expected by use of fewer scanning cycles. Such an SLPFG could be used to develop a promising gas pressure sensor. Furthermore, the pressure sensitivity was effectively enhanced by use of a short hollow silica tube drilled with a micro-channel [30]. 

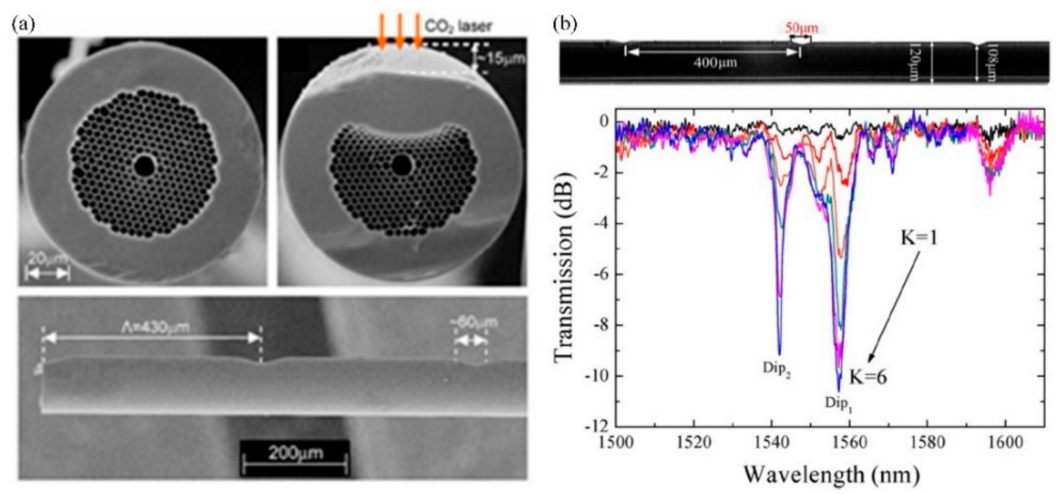

Figure 10. (a) Scanning electron micrographs of SLPFG in air-core photonic bandgap fiber with periodic notches; (b) transmission spectrum evolution of SLPFG while the scanning cycles increases $[27,30]$.

\subsection{Hydrogen-Oxygen Flame Heating Techniques}

As shown in Figure 11, the author developed a novel heat-processing technique, i.e., hydrogen-oxygen flame, to fabricate the HLPFGs. The hydrogen-oxygen flame heating system, consisting of a rotation rotator, two translation stages, and hydrogen-oxygen flame, was developed to fabricate an HLPFG. One end of the fiber was mounted on translation stage-02, another end was fixed along the rotation motor on translation stage-01. During heating, the rotation motor and two translation stages were employed to induce periodic helical structures in the employed fiber. Using this HLPFG inscription method, small numbers of HLPFGs could be obtained by twisting the fiber once. Moreover, various types of HLPFGs in conventional glass fiber [13,17,22] and solid-core PCF [14-16] could be fabricated.

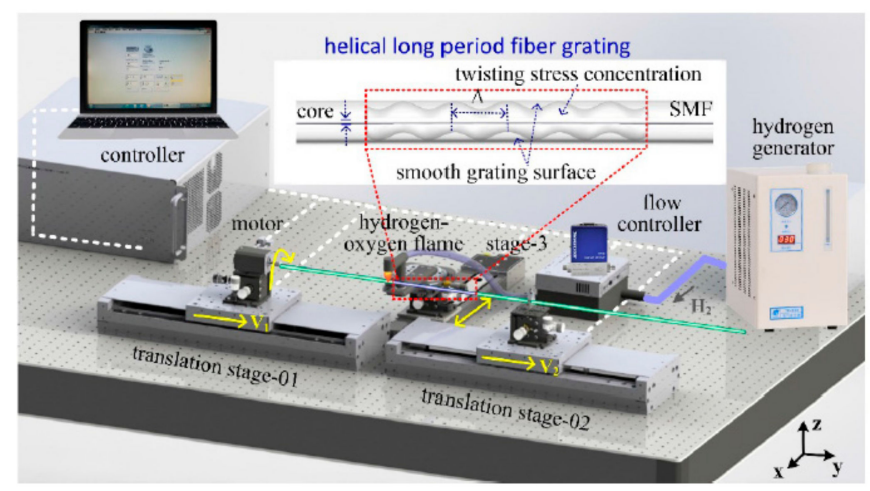

Figure 11. Experimental setup for fabricating the HLPFG [22].

The HLPFG inscription can be described as follows [13]. First, the employed fiber was heated into a fused status with hydrogen-oxygen flame. While the two translation stages moved synchronously with velocities of $v_{1}$ and $v_{2}$, the rotation motor rotated synchronously with a twist rate of $\Omega$. Then an HLPFG with periodic helical refractive index modulation was obtained. In addition, the helical pitch $(\Lambda)$, i.e., grating pitch, was given by the equation $\Lambda=v_{2} \times 60 / \Omega$.

\subsubsection{LPFGs in Conventional Glass Fiber}

As shown in Figure 12a, no obvious physical deformation was observed in the obtained helical fiber, while the decreased diameter, i.e., $122 \mu \mathrm{m}$ was caused by the velocity difference between $\mathrm{v}_{1}$ and $\mathrm{v}_{2}$. In the experiment, $\mathrm{v}_{1}$ and $\mathrm{v}_{2}$ were set as 1.56 and $1.60 \mathrm{~mm} / \mathrm{s}$, respectively. As shown in Figure $12 b$, the resonant wavelength, corresponding to Dip ${ }_{1}$, shifts towards a longer wavelength, and the maximum attenuation decreases from -34.9 to $-3.2 \mathrm{~dB}$, while the length of the helical SMF is cut from 16.8 to $8.4 \mathrm{~mm}$. Then, six HLPFG samples with different grating pitches were also fabricated, 
as shown in Figure 13a. The stability and high-efficiency of the hydrogen-oxygen flame heating system could be reflected by the low insertion loss and strong coupling strength of the HLPFGs. The obtained HLPFG in the SMF with reserved periodic refractive modulations could add helical phase to generate OAM modes.
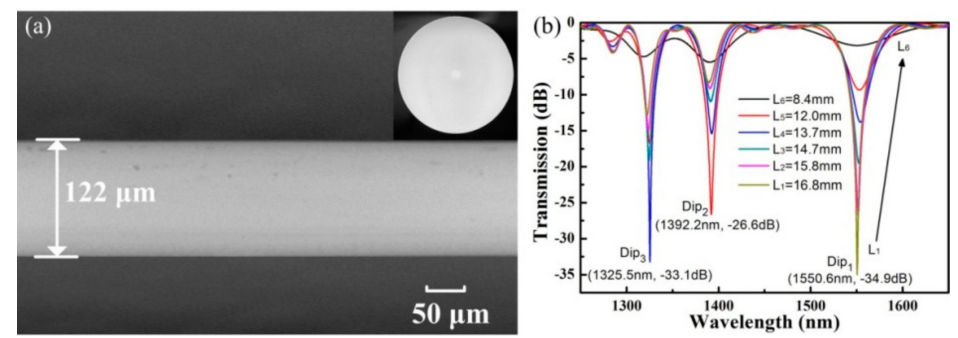

Figure 12. (a) Scanning electron micrographs and (b) transmission spectrum evolution of the HLPFG in SMF while the length decreases [13].
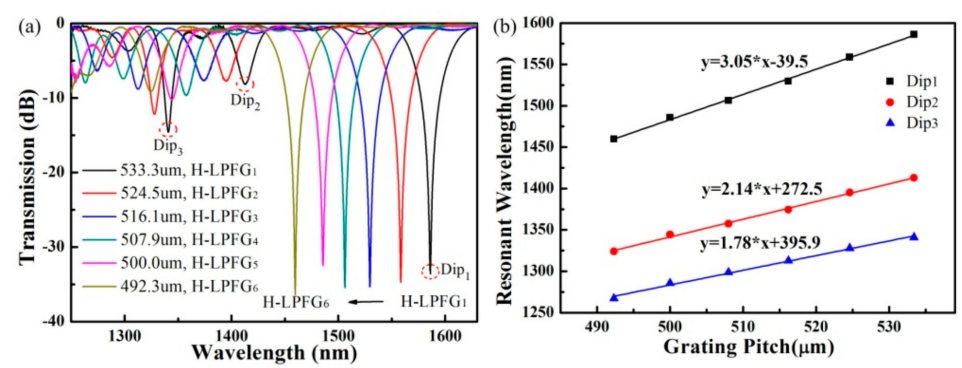

Figure 13. (a) Transmission spectra of six HLPFGs in SMF with different helical grating pitches; (b) measured resonant wavelength of the HLPFG versus helical grating pitch [13].

The right-handed and left-handed HLPFG in four-mode fiber (FMF) were also fabricated by applying the opposite motor directions, i.e., clockwise- or anticlockwise-twisted, respectively [17]. As shown in Figure 14, the resonant wavelength and attenuation were almost same for the righted and left-handed HLPFG in the FMF with a high coupling efficiency up to 99\%. When the light propagated through the HLPFG, every period directly added a helical phase delay to the coupled modes, thus creating an OAM mode. Thus, a resonant enhancement of the helical phase can be formed in the coupled modes, that is, OAM modes.

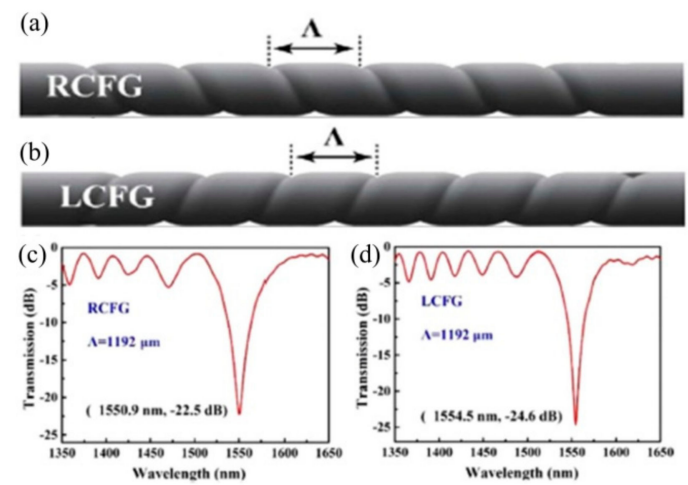

Figure 14. Diagram of periodic helical structure in the (a) right-handed and (b) left-handed HLPFG in four-mode fiber (FMF); Transmission spectra of (c) the right-handed and (d) left-handed HLPFG [17].

\subsubsection{LPFGs in PCF}

A novel HLPFG in a solid-core PCF was fabricated by use of the post-processing method, i.e., hydrogen-oxygen flame heating [14]. After twisting the PCF with $\Omega=115 \mathrm{rpm}, \mathrm{v}_{1}=1.38 \mathrm{~mm} / \mathrm{s}$, and $\mathrm{v}_{2}$ 
$=1.60 \mathrm{~mm} / \mathrm{s}$, a HLPFG was obtained, as shown in Figure 15. When the PCF is gently twisted $(\alpha \Lambda \ll 1)$, the "space-filling" mode (SM) is constrained to forward in a helical trajectory, creating discrete OAM modes [18].

Six HLPFG samples with different twist rates were fabricated. As shown in Figure $15 c, d$ the resonant wavelength $\left(\lambda_{R}\right)$ shifted to a longer wavelength with the increase of the twist rate. Moreover, the equation of the resonant wavelength $\left(\lambda_{R}\right)$ is:

$$
\lambda_{R}=2 \pi \mathrm{n}_{S M} \rho^{2} \alpha /|l|
$$

The product $\mathrm{n}_{\mathrm{SM}} \rho^{2}$ is a constant for a given PCF. Then the resonance dips, i.e., Dip ${ }_{1}$ and $\mathrm{Dip}_{2}$, of the HLPFG in PCF in Figure 15 could generate $\mathrm{OAM}_{+6}$ and $\mathrm{OAM}_{+5}$ modes, respectively.
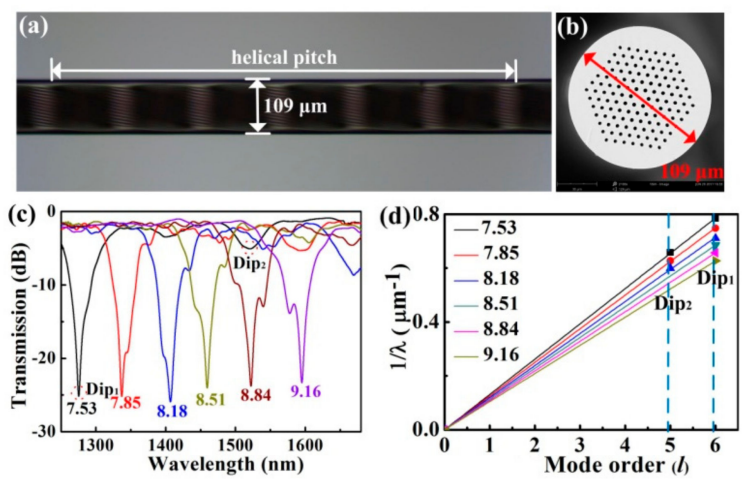

Figure 15. (a) Side-view and (b) cross-section microscope images of the HLPFG in PCF; (c) transmission spectra of six HLPFG samples with different twist rates; (d) reciprocal resonant wavelength $\left(\lambda_{R}\right)$ in units of at $\mu \mathrm{m}^{-1}$ plotted against mode order for the experimental data [14].

Furthermore, an improved hydrogen-oxygen flame heating system for fabricating an inflated HLPFG (I-HLPFG) in the PCF was built by adding an air pump in the experimental setup in [13]. As shown in Figure 16c,d, the clockwise-twisted (CT) and anticlockwise-twisted (ACT) IHLPFG with an opposite periodic pattern of the helical air holes on the fiber surface, were fabricated by applying opposite directions of the rotation motor [15]. As shown in Figure 17a,b, compared with un-inflated HLPFG, i.e., an air hole diameter of $2.9 \mu \mathrm{m}$, the air holes in IHLPFG exhibited a larger diameter, i.e., $3.6 \mu \mathrm{m}$, due to the inflated gas pressure of $0.8 \mathrm{MPa}$.

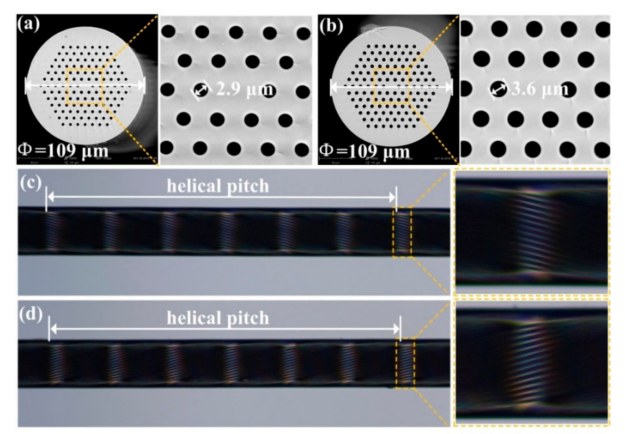

Figure 16. Cross-section of the (a) HLPFG and (b) inflated HLPFG (I-HLPFG) in the PCF; side-view microscope images of the (c) clockwise-twisted (CT)- and (d) anticlockwise-twisted (ACT)-IHLPFG [15].

Compared with the IHLPFGs, as shown in Figure 17, the resonant wavelength of the HLPFGs shifts toward a longer wavelength under the same twist rate condition. Moreover, the distinct splits in the HLPFG are attributed to an asymmetric refractive index modulation. In contrast, the perfect resonant dips without splits were obtained for the IHLPFG, owing to the inflated high-pressure air 
avoiding the uneven shrinkage of the air holes in cladding. Thus, a perfect IHLPFG could be achieved by means of an inflation-assisted hydrogen-oxygen flame heating technique.
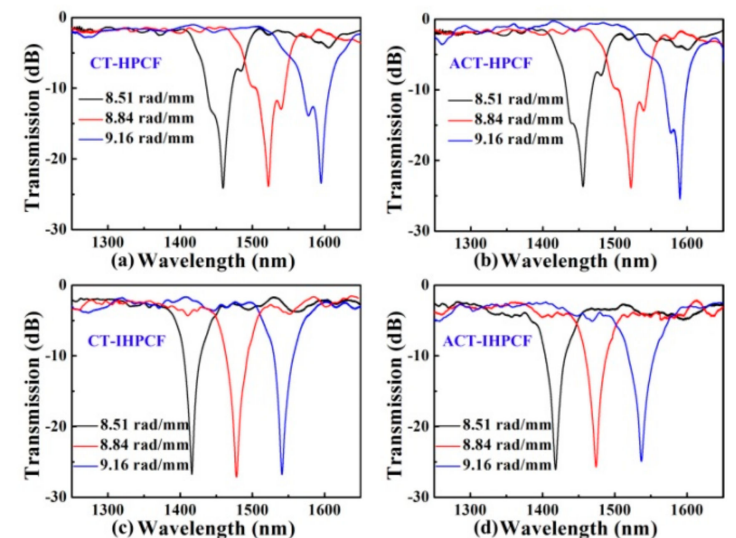

Figure 17. Transmission spectra for (a) CT-HLPFG; (b) ACT-HLPFG; (c) CT-IHLPFG; and (d) ACT-IHLPFG [15].

\subsection{Arc Discharge Heating Techniques}

Arc discharge heating techniques have drawn attention owing to their simplicity, flexibility, and thermal stability. The possible mechanisms of the LPFG formation are geometrical deformation, stress relaxation, and structure changes.

A high-temperature stability SLPFG in S-doped and N-doped fiber was fabricated using the arc discharge technique [92]. The origin of antisymmetric perturbation of the fiber in arc-induced SLPFGs that couple the core mode into the antisymmetric $\mathrm{LP}_{1 \mathrm{i}}$ cladding modes is the temperature gradient in the arc discharge. This gradient causes a temperature gradient in the fiber, which results in a gradient of viscosity and a corresponding asymmetry of fiber deformation [93]. In addition, the PDL of the SLPFGs strongly depends on the arc discharge fabrication parameters (electric current, arc duration, and pulling tension) [34]. Esposito et al. has made a detailed review concerning the fabrication of SLPFGs in several fibers, i.e., silica optical fiber with both different dopants and geometrical structures, by means of arc discharge heating technique [94].

As shown in Figure 18, a commercial fusion splicer (ARC master FSM-100P+) with a second program development, consisting of three motors, i.e., ZL, ZR, and SWEEP motors, is employed to fabricate the SLPFG by periodically tapering the SMF [35]. Firstly, the down-taper and up-taper are formed by synchronously stretching the fiber with ZR and ZL motors. Secondly, the second taper pitch was realized by the SWEEP motor. The velocities of the ZL and ZR motors are $v_{1}$ and $v_{2}$, respectively. In addition, the pulling velocity $\mathrm{v}_{1}$ is determined by the equation $\mathrm{v}_{1}=\left(\mathrm{d}_{1} / \mathrm{d}_{2}\right)^{2} \mathrm{v}_{2}$, where $\mathrm{d}_{1}$ and $\mathrm{d}_{2}$ are the diameters of SMF and the processed taper, respectively. Therefore, the proposed arc discharge technique could be used to inscribe SLPFGs with periodic tapers [65].
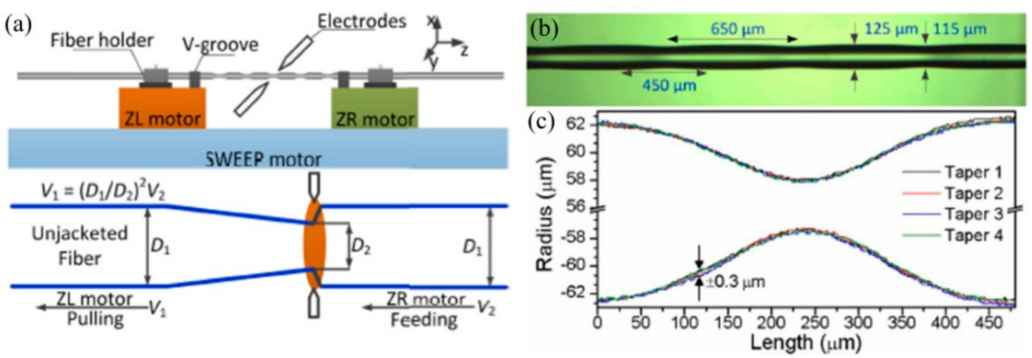

Figure 18. (a) Schematic diagram for inscribing a LPFG with periodic tapers; (b) side-view microscope images of periodic taper; (c) shape profiles of four tapers [35]. 
Subsequently, Yin et al. also developed an automatic arc discharge heating technology to simultaneously fabricate the SLPFGs in the SMF and PCF [36]. As shown in Figure 19, the obtained SLPFGs sample in SMF and PCF have no obvious deformation on the surface. It takes only 25 and 60 arc discharges periods to reach the dip attenuation of $20 \mathrm{~dB}$ in SMF and PCF, respectively. The improved fabrication efficiency is attributed to the appropriate arc duration and current.

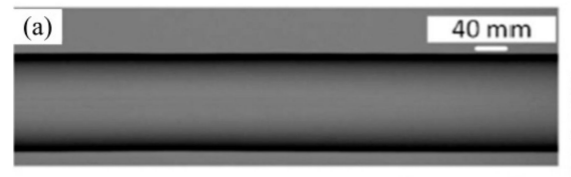

(b)

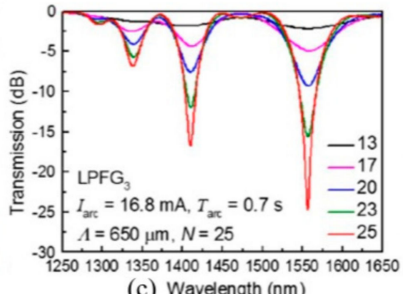

(c) Wavelength $(\mathrm{nm})$

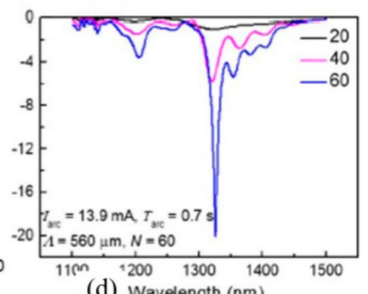

(d) Wavelength $(\mathrm{nm})$

Figure 19. Side-view microscope images of fabricated SLPFG in (a) SMF and (b) PCF; transmission spectrum of the SLPFG in (c) SMF and (d) PCF [36].

To avoid the air holes in the cladding region collapsing, Iadicicco et al. used a modified pressure-assisted arc discharge heating technique to fabricate SLPFGs in air-core PBF, as shown in Figure 20. The combination consisted of an electric arc discharge, to locally heat the fiber, and a static pressure, to preserve the holey structure of the PBF. A static pressure was forced into the air holes by means of connecting a small air pump with the air-core PBF [95]. Subsequently, they reported about the fabrication of SLPFGs in polarization-maintaining fiber by means of arc discharge heating technique, regardless of the fiber orientation during the fabrication process. The transmission spectrum was dependent on the state of the input light polarization, i.e., the fast and slow axes of the Panda fiber [96].
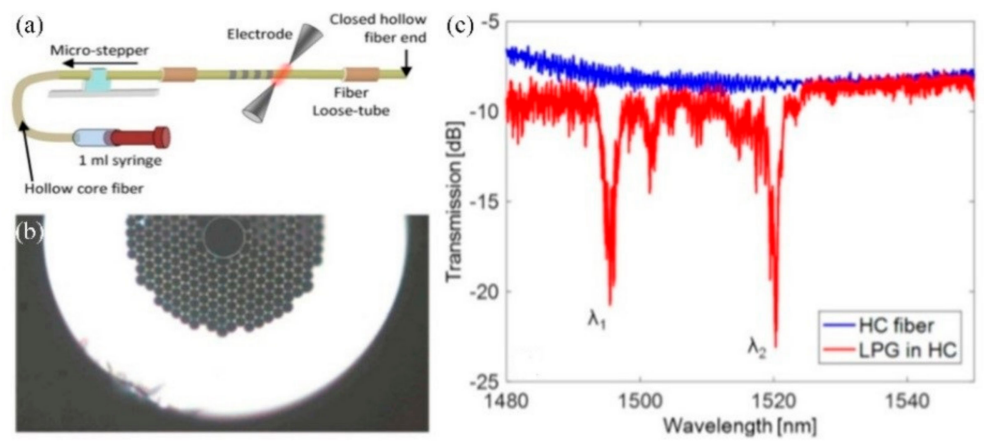

Figure 20. (a) Schematic diagram; (b) microscopy image; and (c) transmission spectra of the SLPFG in air-core PBF by using the pressure-assisted arc discharge heating technique [95].

Arc discharge heating techniques could also be employed to fabricate the HLPFG. Sun et al. employed a commercial fusion splicer, i.e., an automatic arc discharge heating technique, to inscribe high-quality HLPFGs in SMF [37], as shown in Figure 21. The HLPFG inscription program involved two motors, i.e., $\theta_{\mathrm{L}}$ and SWEEP motors. The $\theta_{\mathrm{L}}$ motor with the twist speed was used to determine the time for rotating a period, while the SWEEP motor was to move the fiber according to the grating pitch of the HLPFG. Then, the arc-induced screw-type refractive index modulation was formed in the HLPFGs. The achieved HLPFGs have been reported to have potential usage as sensors in temperature, refractive index, twist stress, and strain. 


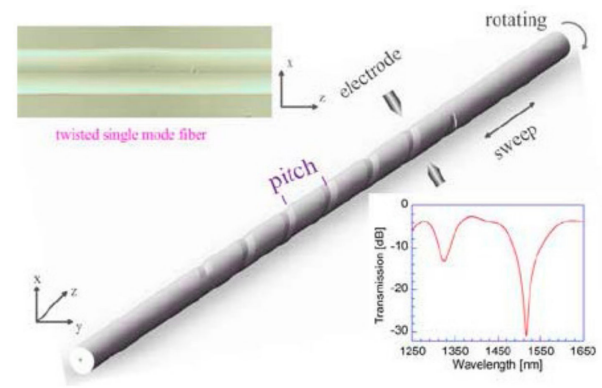

Figure 21. Schematic diagram of fabricated HLPFG in SMF [37].

Li et al. presented a high-repeatability and -stability arc discharge technique based on the secondary exploration of the splicer [38]. As shown in Figure 22, the attenuation of the resonance dip for HLPFG in an all-solid PBF reached up to $30 \mathrm{~dB}$ with only two periods. During the fabrication process, the appropriate arc strength, the velocity of the translation and rotation motor are vital to the quality of the HLPFG in all-solid PBF.
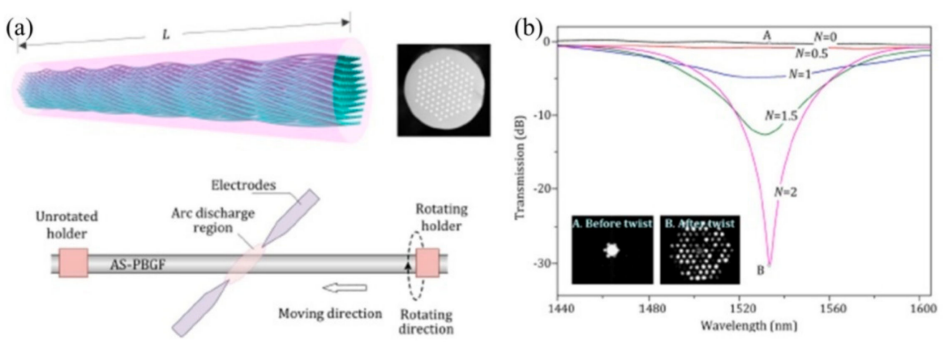

Figure 22. (a) Schematic diagrams and (b) transmission spectra of HLPFG in all-solid PBF using the arc discharge heating techniques [38].

\section{OAM Mode Converters}

Orbital angular momentum (OAM) mode is characterized by a dark hollow center with phase or polarization singularities, which has potential applications in various fields, such as optical communications, detection of rotating objects, and optical tweezers. Achieving a higher transmission capacity of the optical communication system could be realized by using mode-division multiplexing (MDM) technique based on the generated all-fiber OAM modes. Recently, many spatial OAM mode converters have been demonstrated, such as spatial light modulators [97], phase plates [98], integrated silicon devices [99] and micrometer-scale meta-materials [100]. However, these spatial OAM mode converters have an obvious coupling loss when integrated with the existed optical fiber communication system. A key device is a mode converter, i.e., coupling from the fundamental core mode to high-order mode, which utilizes the generated OAM modes to realize the MDM. Recently, various all-fiber OAM mode converters based on SLPFGs or HLPFGs in different types of fibers have been reported, due to their low loss, high coupling efficiency and easy fabrication.

\subsection{OAM Mode Converters Based on SLPFGs}

As shown in Figure 23, Li et al. proposed a controllable all-fiber OAM mode converter, consisting of a two-mode fiber (TMF), a mechanical-induced LPFG, a mechanical rotator, metal flat slabs, and a polarization controller [51].The mechanical-induced SLPFG converted the core mode to the high-order modes, and then a specific relative phase difference was achieved in combination of the rotator with flat slabs. By adjusting (stressing, rotating, and twisting) the mechanical device, an input $\mathrm{LP}_{01}$ mode from the SMF could be selectively converted to the $\mathrm{LP}_{11 \mathrm{a}}, \mathrm{LP}_{11 \mathrm{~b}}, \mathrm{OAM}_{-1}$, or $\mathrm{OAM}_{+1}$ modes at the output terminal of the TMF. 


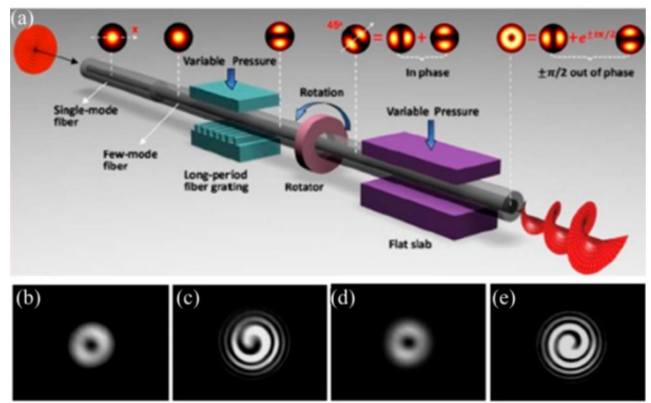

Figure 23. (a) Principle of the controllable all-fiber orbital angular momentum (OAM) mode converter. $(\mathbf{b}, \mathbf{d})$ intensity; and $(\mathbf{c}, \mathbf{e})$ interference pattern of the generated $\mathrm{OAM}_{ \pm 1}$ modes [51].

To enhance the stability of the OAM mode converter, Zhao et al. employed permanent $\mathrm{CO}_{2}$-laser-inscribed uniform and tilted SLPFGs in the TMF to be used as an OAM mode converter [52]. The mode conversion efficiency of the fabricated SLPFGs between $\mathrm{LP}_{01}$ mode and $\mathrm{LP}_{11}$ mode could be up to $99 \%$. Moreover, the bandwidth and conversion efficiency of the tilted SLPFG, i.e., OAM mode converter, could be tuned by adjusting the fabrication tilt angle. As shown in Figure 24, two orthogonal vector modes (the $\mathrm{HE}_{21}{ }^{\text {even }}$ and $\mathrm{HE}_{21}$ odd modes) could be successfully generated by adjusting the polarization controllers in the uniform and tilted SLPFGs, thus generating the corresponding OAM modes at the resonant wavelength.

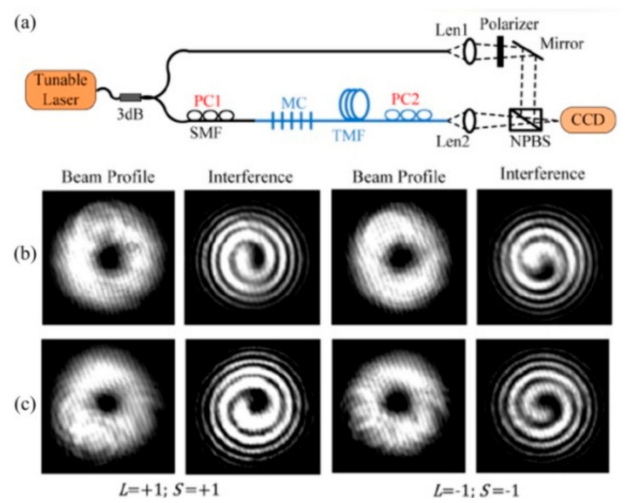

Figure 24. (a) Experimental setup used to excite the OAM modes; beam profile and interference patterns of the generated OAM modes using (b) SLPFG and (c) tilted SLPFG, respectively [52].

Subsequently, the $\mathrm{CO}_{2}$-laser-inscribed SLPFGs in the FMF are also employed to generate the $\mathrm{OAM}_{ \pm 1}$ and $\mathrm{OAM}_{ \pm 2}$ modes [53], as shown in Figure 25. A single SLPFG could be used to convert the $\mathrm{LP}_{01}$ mode to $\mathrm{LP}_{11}, \mathrm{LP}_{21}$, and $\mathrm{LP}_{02}$ modes with a conversion efficiency of $99 \%$. Moreover, an optimized $\mathrm{LP}_{01}-\mathrm{LP}_{21}$ mode converter with a maximum conversion efficiency of $\sim 99.5 \%$ can be obtained by use of cascaded SLPFGs with different grating pitches. The low- and high-order OAM modes, i.e., $\mathrm{OAM}_{ \pm 1}$ and $\mathrm{OAM}_{ \pm 2}$ modes, are experimentally generated using the $\mathrm{CO}_{2}$-laser-inscribed SLPFGs in the FMF. 


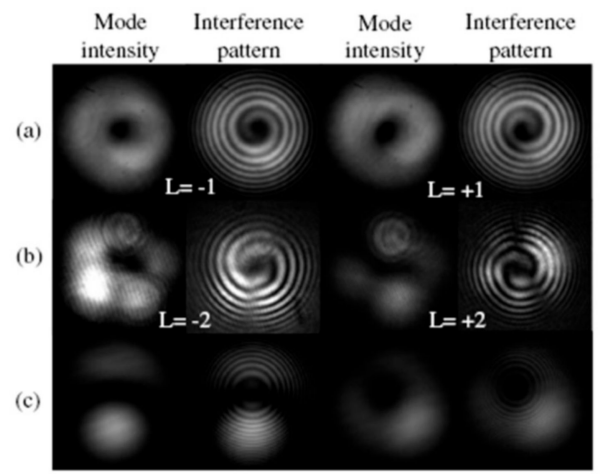

Figure 25. The generated $\mathrm{OAM}_{ \pm 1}$ and $\mathrm{OAM}_{ \pm 2}$ modes by using the three single SLPFG mode converters: (a) $\mathrm{LP}_{01}-\mathrm{LP}_{11} ;$ (b) $\mathrm{LP}_{01}-\mathrm{LP}_{21}$; and (c) $\mathrm{LP}_{01}-\mathrm{LP}_{02}$ [53].

A single $\mathrm{CO}_{2}$-laser-induced SLPFG with strong periodic deformation inscribed in the FMF is used to directly convert the $\mathrm{LP}_{01}$ mode to an $\mathrm{LP}_{21}$ core mode. Then, a high-order OAM mode converter, i.e., $\mathrm{OAM}_{ \pm 2}$, via twisting a strong modulated SLPFG written in a FMF, was proposed and experimentally demonstrated [54]. As shown in Figure 26, we can directly convert the $\mathrm{LP}_{01}$ to $\mathrm{LP}_{21}$ with a conversion efficiency of $99.7 \%$ and then transform the $\mathrm{LP}_{21}$ mode into $\mathrm{OAM}_{ \pm 2}$ by adjusting the polarization controller and rotator. It is the first time that $\mathrm{OAM}_{ \pm 2}$ modes were generated by only one SLPFG in FMF.

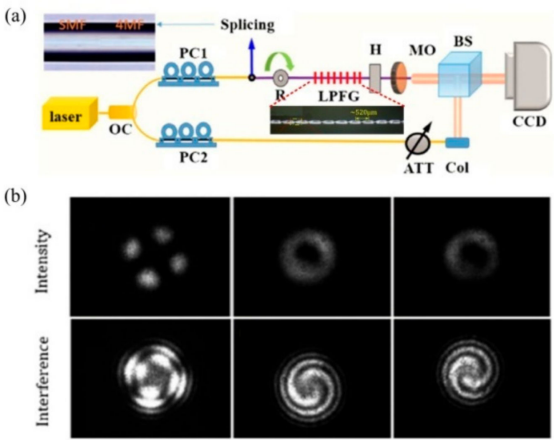

Figure 26. (a) Experimental setup for generating and detecting the OAM modes; (b) intensity profiles and interference patterns of the generated $\mathrm{OAM}_{ \pm 2}$ modes by only using one strong modulated SLPFG in FMF [54].

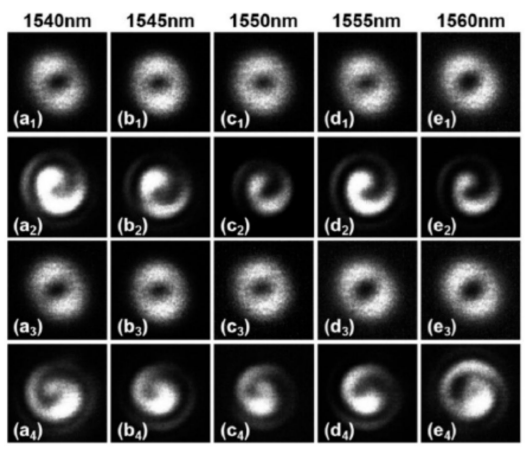

Figure 27. Mode intensities ( $\left.\mathbf{a}_{1}-\mathbf{e}_{1}\right)$ and $\left(\mathbf{a}_{3}-\mathbf{e}_{3}\right)$, interference patterns $\left(\mathbf{a}_{2}-\mathbf{e}_{2}\right)$ and $\left(\mathbf{a}_{4}-\mathbf{e}_{4}\right)$ of the generated $\mathrm{OAM}_{ \pm 1}$ modes via acoustically-induced fiber grating (AIFG) at different resonant wavelengths [55].

Zhang et al. realized the generation of the optical vortex with a wavelength tenability by using an acoustically-induced fiber grating (AIFG) [55]. As shown in Figure 27, the OAM mode could be generated from 1540 to $1560 \mathrm{~nm}$ by dynamically adjusting the frequency of the driving signal, i.e., radio frequency signal. The left- and right-handed circular polarization fundamental mode could 
be converted to the $\mathrm{OAM}_{+1}$ and $\mathrm{OAM}_{-1}$ modes, respectively, in the TMF using the AIFG with a conversion efficiency of $\sim 95 \%$.

Then, a high-order OAM mode converter, i.e., $\mathrm{OAM}_{ \pm 2}$ mode, was proposed by using the cascaded AIFG in the few-mode fiber [56]. As shown in Figure 28, the first AIFG was used to convert the circular polarization core mode to $\mathrm{OAM}_{ \pm 1}$, and then to convert the $\mathrm{OAM}_{ \pm 1}$ mode to $\mathrm{OAM}_{ \pm 2}$ mode through the second AIFG. In the experiment, the two AIFGs were driven by two different radio frequencies.

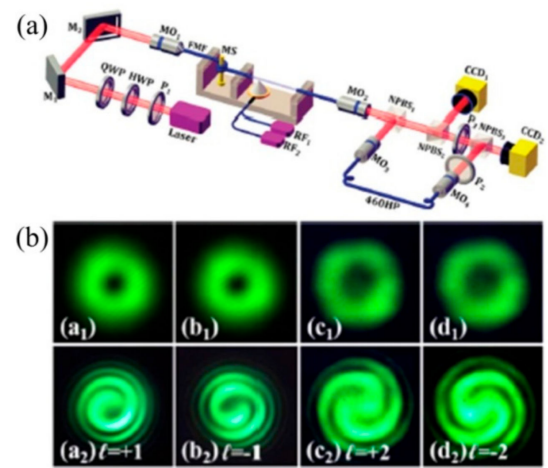

Figure 28. (a) Experimental setup for generating the OAM mode by using the cascaded AIFG; (b) beam profiles and interference patterns of the $\mathrm{VM}_{11}{ }^{ \pm}$and $\mathrm{VM}_{21}{ }^{ \pm}[56]$.

In addition, the OAM modes based on SLPFG in air-core PBF have been obtained by superposing vector modes $\mathrm{HE}_{21} \mathrm{e}, \mathrm{o}$, because the effective refractive index separation of the second group of vector modes is around $10^{-4}$. Moreover, as shown in Figure 29, the phased delay between $\mathrm{HE}_{21}{ }^{\mathrm{e}}$ and $\mathrm{HE}_{21}{ }^{\mathrm{o}}$ has been adjusted by changing the polarization states of the input fundamental mode, and the topology charge of OAM has been tuned from -1 to +1 as well [50].

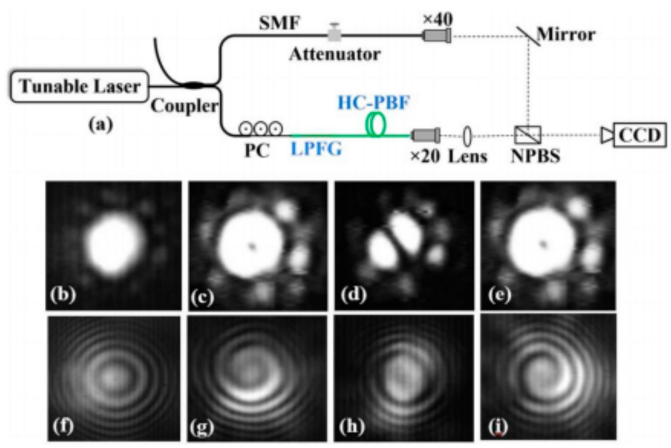

Figure 29. (a) Schematic diagrams for generating the OAM modes; (b-e) mode intensities and $(\mathbf{f}-\mathbf{i})$ interference patterns of the generated OAM modes [50].

\subsection{OAM Mode Converters Based on HLPFGs}

OAM mode converters based on above-mentioned LPFGs require external devices, e.g., rotators, polarizers, and polarization controllers, to regulate the polarization direction or phase difference, which gives rise to a complex system. Then, the OAM modes could be generated only at specific phase difference. Wong et al. demonstrated, for the first time, the excitation of OAM modes in a continuously twisted solid-core PCF, but no OAM modes were experimentally observed due to a weak coupling [18].Then, $\mathrm{Xi}$ et al. studied the properties of a continuously twisted PCF with a novel three-bladed core that preserves the chirality of OAM modes of the same order, i.e., it inhibits scattering between an order +1 mode to an order -1 mode [20]. This is of potential interest for increasing channel capacity in optical telecommunications.

A novel all-fiber low-order OAM mode convertor based on HLPFG in SMF is demonstrated in Figure 30 by means of hydrogen-oxygen flame heating technique [13]. The purity and conversion 
efficiency of the generated $\mathrm{OAM}_{+1}$ mode are $91 \%$ and $87 \%$, respectively. Moreover, the resonant wavelength of the HLPFGs, i.e., OAM mode converter, could be adjusted by changing the twist rate. In other words, the $\mathrm{OAM}_{+1}$ mode in the HLPFG could be generated within a large wavelength region using the HLPFG in SMF.

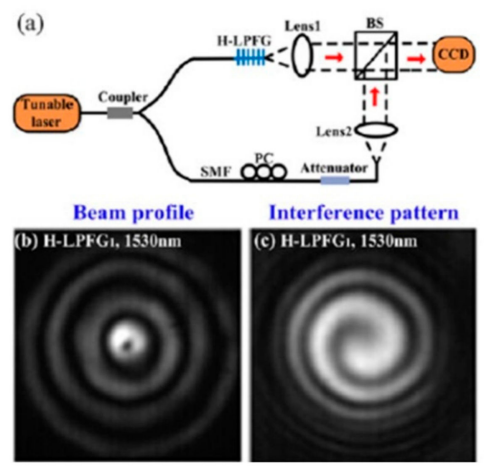

Figure 30. (a) Schematic diagram of experimental setup for detecting the generated OAM modes; $(\mathbf{b}, \mathbf{c})$ beam profile and interference pattern of the generated $\mathrm{OAM}_{+1}$ mode by the HLPFG in SMF at the resonant wavelength [13].

Then, the authors have demonstrated a polarization independent $\mathrm{OAM}_{ \pm 1}$ mode converter based on HLPFG in TMF [17]. As shown in Figure 31, the $\mathrm{OAM}_{+1}$ and $\mathrm{OAM}_{-1}$ modes could be generated by the right- and left-handed HLPFG at different polarization states of the input light, indicating that the OAM mode converter based on HLPFG in TMF is polarization independent.

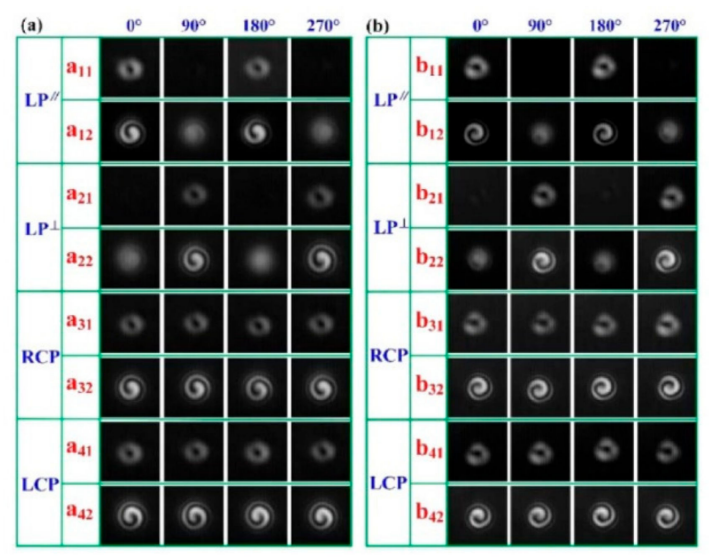

Figure 31. Beam profiles and interference patterns of the generated (a) $\mathrm{OAM}_{+1}$ modes and (b) $\mathrm{OAM}_{-1}$ modes by using right-handed and left-handed HLPFG in TMF, respectively [17].

A special twisted three-bladed core PCF has generated an $\mathrm{OAM}_{ \pm 1}$ mode [20]. In-fiber high-order OAM mode converters could be used to achieve a higher data transmission capacity in an all-fiber optical communication system. A high-order OAM mode converter, i.e., $\mathrm{OAM}_{+6}$ and $\mathrm{OAM}_{+5}$, is achieved by a HLPFG in the PCF. As shown in Figure 32, the resonance dips, i.e., Dip 1 and Dip 2 , of the HLPFG generated $\mathrm{OAM}_{+6}$ and $\mathrm{OAM}_{+5}$ modes [14]. Compared with [18], the reason for the successful observation of the generated OAM mode is a higher attenuation, i.e., $-20 \mathrm{~dB}$. Moreover, the resonant wavelength and attenuation of the HLPFG are determined by the twist rate (i.e., grating pitch) and coupling length. 


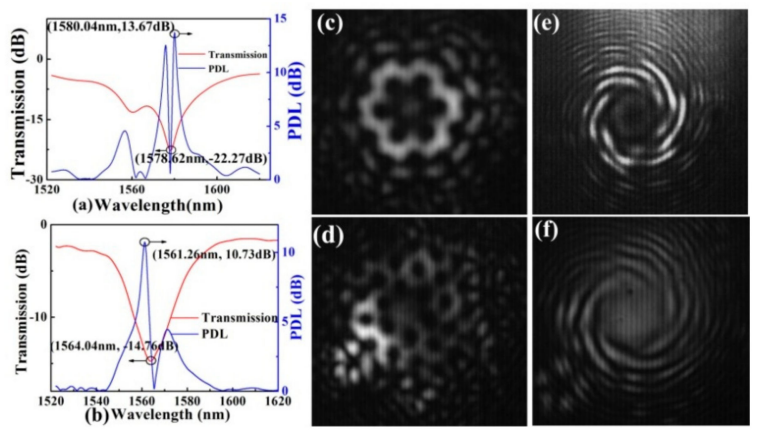

Figure 32. Transmission spectrum of the (a) $\operatorname{Dip}_{1}(\mathbf{b})$ and $\operatorname{Dip}_{2} ;(\mathbf{c}, \mathbf{d})$ measured beam profiles and (e,f) interference patterns of the Dip 1 and Dip2 in the HLPFG, i.e., $\mathrm{OAM}_{+6}$ and $\mathrm{OAM}_{+5}$ modes generated by the HLPFG in the PCF [14].

Furthermore, as shown in Figure 33, a high-order twist-direction-dependent $\mathrm{OAM}_{ \pm 6}$ mode converter was achieved by an IHLPFG in the PCF [15]. Compared with un-inflated HLPFG in the $\mathrm{PCF}$, the OAM mode converter based on IHLPFG generated a high-quality $\mathrm{OAM}_{ \pm 6}$ mode due to a perfect transmission dip without distinct splits. In addition, the order of the generated OAM modes was determined by the twist direction i.e., CT- and ACT-IHLPFG. Moreover, the polarization state of the input light, i.e., parallel linearly polarized (PLP), vertical linearly polarized (VLP), left circularly polarized (LCP) and the right circularly polarized (RCP) light has no effect on the order of the generated OAM mode.

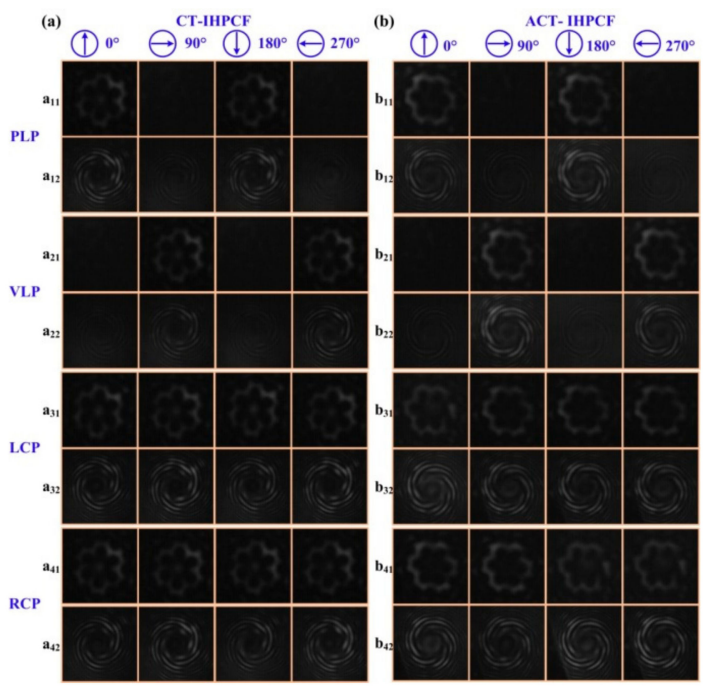

Figure 33. $\mathrm{OAM}_{ \pm 6}$ modes generated by the (a) CT- and (b) ACT-IHLPFG in the PCF at different polarization states of the input light [15].

\section{Strain Sensors}

The resonant wavelength will shift when the strain is applied to the LPFG, resulting from its stretched helical pitch or periodic micro-bends [25]. As a result, the LPFGs could be used as strain sensors.

A temperature-independent strain SLPFG sensor is fabricated by carving grooves periodically along a twisted SMF with high-frequency $\mathrm{CO}_{2}$ laser. The separation change between the two split peaks of SLPFGs exhibited a high strain sensitivity of about $106.7 \mathrm{pm} / \mu \varepsilon$ [61]. Moreover, using a phase-shifted SLPFG fabricated by $\mathrm{CO}_{2}$ laser beam, a temperature-insensitive sensor that allows for large axial strain measurement with a value up to $7600 \mu \varepsilon$ is demonstrated [62]. Ren et al. developed a strain sensor with a sensitivity of $1.2 \mathrm{pm} / \mu \varepsilon$ based on a microtapered SLPFG fabricated by periodically tapering a 
SMF with $\mathrm{CO}_{2}$ laser heating source [63]. Furthermore, two peaks of the novel high-sensitivity strain sensor fabricated by weak power modulation of $\mathrm{CO}_{2}$ laser exposure on a tapered LPFG exhibited sensitivities of 1.82 and $8.17 \mathrm{pm} / \mu \varepsilon$, respectively [64].

A SLPFG strain sensor based on PCF with a high strain sensitivity of $-7.6 \mathrm{pm} / \mu \varepsilon$ and a low temperature sensitivity of $3.91 \mathrm{pm} /{ }^{\circ} \mathrm{C}$ is achieved by use of a focused $\mathrm{CO}_{2}$ laser beam carving periodic grooves on the fiber [57]. Such a strain sensor can effectively reduce the cross-sensitivity between strain and temperature, and the temperature-induced strain measurement error is only $0.5 \mu \varepsilon /{ }^{\circ} \mathrm{C}$ in the case of no temperature compensation. Another high-sensitivity strain sensor based on an inflated SLPFG (I-SLPFG) was fabricated by use of the pressure-assisted $\mathrm{CO}_{2}$ laser beam scanning technique to periodically inflate air holes of the PCF. As shown in Figure 34, such periodic inflations of the holes enhanced the strain sensitivity of the ISLPFG to $-5.62 \mathrm{pm} / \mu \varepsilon$ [48]. In addition, after high temperature annealing, the I-SLPFG demonstrated a good repeatability and stability of temperature response, and a sensitivity of $11.92 \mathrm{pm} /{ }^{\circ} \mathrm{C}$ was achieved.
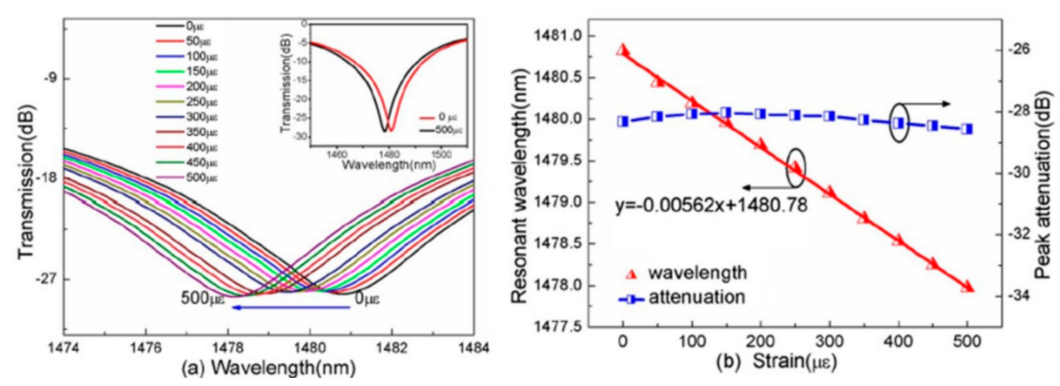

Figure 34. (a) Transmission spectrum evolution of the strain sensor based on ILPFG with a sensitivity of $-5.62 \mathrm{pm} / \mu \varepsilon ;(\mathbf{b})$ measured resonant wavelength and peak attenuation as a function of the strain [48].

Strain sensors based on HLPFG have also been developed. The strain sensitivities of HLPFGs fabricated by twisting SMF during $\mathrm{CO}_{2}$ laser irradiation are characterized in terms of both spectral shift and transmission power variation. Results show that the resonant wavelength shift sensitivity and transmission power sensitivity are $-1.1 \mathrm{pm} / \mu \varepsilon$ and $2.2 \times 10^{-4} \mathrm{~dB} / \mu \varepsilon$, respectively [58]. In addition, a novel strain sensor based on two successively cascaded HLPFGs exhibits a sensitivity of $-0.185 \mathrm{pm} / \mu \varepsilon$ [59]. A highly sensitive strain sensor with a sensitivity of $-61.8 \mathrm{pm} / \mu \varepsilon$ based on helical structure-assisted Mach-Zehnder interference in an all-solid heterogeneous multi-core fiber was proposed and experimentally demonstrated [60]. Xi et al. investigated a strain sensor with a sensitivity of $-1.18 \mathrm{pm} / \mu \varepsilon$ based on HLPFG in the PCF, and the analysis showed that the tension-induced shift in resonance wavelength is determined both by the photoelastic effect and the change in twist rate [19]. The author also proposed a strain sensor with similar sensitivities of -3.20 and $-3.18 \mathrm{pm} / \mu \varepsilon$ based on the HLPFG and I-HLPFG in the PCF [16].

\section{Pressure Sensors}

Various grating-based pressure sensors are of great interest owing to their easy fabrication, compact size, and robustness. The resonant wavelength of the LPFG would be observed by the red or blue shifts with the change of pressure (transverse load).

A compact reflective type of pressure sensor based on tapered SLPFGs fabricated by means of a computer-assisted precision arc-discharge apparatus in SMF had a sensitivity of $0.51 \mathrm{pm} / \mathrm{MPa}$ [65]. Then, a pressure sensor based on tapered SLPFGs in PCF displayed a pressure sensitivity of $1.12 \mathrm{pm} / \mathrm{MPa}$ [66]. Subsequently, Zhong et al. demonstrated an I-LPFG in the PCF by use of the pressure-assisted $\mathrm{CO}_{2}$ laser beam-scanning technique to periodically inflate air holes of a PCF along the fiber axis. Such an I-SLPFG exhibited a pressure sensitivity of $1.68 \mathrm{~nm} / \mathrm{MPa}$, which is higher than the SLPFG without inflation. Moreover, the I-SLPFG exhibited a low temperature sensitivity, i.e., $3.1 \mathrm{pm} /{ }^{\circ} \mathrm{C}$, due to the 
inherent pure silica material, resulting in a low $1.8 \mathrm{Kpa} /{ }^{\circ} \mathrm{C}$ cross-sensitivity in the case of no temperature compensation [29].

Tang et al. reported a gas pressure sensor with periodic collapses of air holes in an air-core PBF fabricated by use of focused $\mathrm{CO}_{2}$ laser beam [30]. The gas pressure sensor exhibited a pressure sensitivity of $-137 \mathrm{pm} / \mathrm{MPa}$ due to the gas-pressure-induced stress concentration at the collapse region of the LPFG in PBF. Then, an improved gas pressure sensor constructed by a short hollow silica tube segment with a SLPFG in PBF was proposed [31]. A micro-channel in the middle of the hollow silica tube was introduced by use of the femtosecond laser technique to allow the air-core of the hollow core PBF to be exposed to the external gas surroundings. The gas pressure sensitivity of the sensor was increased to $-1.3 \mathrm{~nm} / \mathrm{MPa}$. Moreover, the temperature sensitivity of the gas-pressure sensor was as low as $5.3 \mathrm{pm} /{ }^{\circ} \mathrm{C}$.

Furthermore, the HLPFG and I-HLPFG with different air-hole diameters, i.e., 2.9 and $3.6 \mu \mathrm{m}$, could be used as a pressure senor [16]. The transverse-load sensitivity, i.e., $15.50 \mathrm{~nm} /\left(\mathrm{N} \cdot \mathrm{mm}^{-1}\right)$, of the IHLPFG with an air-hole diameter of $3.6 \mu \mathrm{m}$ was higher than the transverse-load sensitivity of the HLPFG with an air-hole diameter of $2.9 \mu \mathrm{m}$, i.e., $4.45 \mathrm{~nm} /\left(\mathrm{N} \cdot \mathrm{mm}^{-1}\right)$, as shown in Figure 35. In other words, we could greatly enhance the transverse-load sensitivity by enlarging the diameter of the air holes in the I-HLPFG.
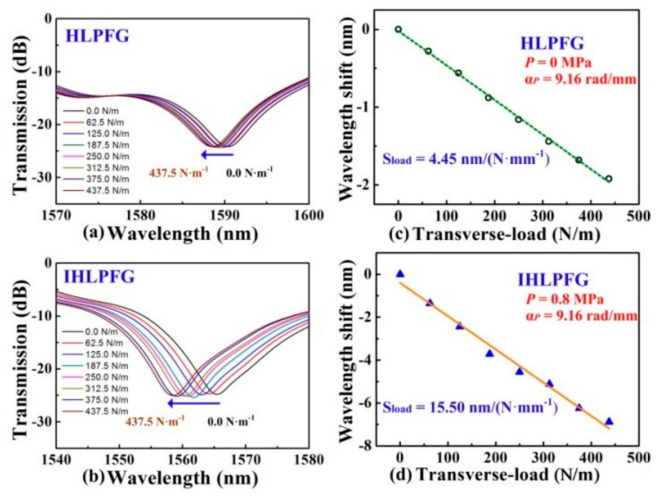

Figure 35. Transmission spectrum evolution of the (a) HLPFG and (b) I-HLPFG in PCF with air-hole diameters of 2.9 and $3.6 \mu \mathrm{m}$, respectively; measured resonant wavelength shift of the (c) HLPFG and (d) I-HLPFG as a function of the transverse load [16].

\section{Torsion Sensors}

Torsion sensors are widely used in various applications due to their high torsion sensitivity. Various types of optical fiber torsion sensors, such as corrugated SLPFGs [101], high-birefringence fibers [102], polarization-maintaining FBGs [103], Sagnac loops [104,105], and distributed FBGs [106] have been demonstrated. Unfortunately, the torsion directions, i.e., clockwise- or anticlockwise-twisted, could not be distinguished by these devices. Wang et al. reported that a $\mathrm{CO}_{2}$-laser-induced LPFG could not only measure the applied twist rate but also distinguish simultaneously the torsion direction, i.e., the resonant wavelength of the $\mathrm{CO}_{2}$-laser-induced SLPFG shifts linearly toward the longer wavelength under clockwise torsion, while the opposite process occurred under anticlockwise torsion $[107,108]$.

A novel pre-twisted LPFG with periodic reserved screw-type deformations was developed to be a torsion sensor to distinguish not only the torsion angle but also the torsion direction [46]. As shown in Figure 36, the opposite resonant wavelength shifts with sensitivities of 160.4 and $113.0 \mathrm{~nm} /\left(\mathrm{rad} \cdot \mathrm{mm}^{-1}\right.$ ) were observed for the right- and left-helix pre-twisted LPFGs. The resonant wavelengths of the HLPFG in SMF fabricated by automatic arc discharge heating technique vary monotonically and linearly with a torsion sensitivity of $-46.46 \mathrm{~nm} /\left(\mathrm{rad} \cdot \mathrm{mm}^{-1}\right)$ [37]. A type of few-period helically twisted all-solid PBF produces mechanical torsion sensitivities of $115.5 \mathrm{~nm} /\left(\mathrm{rad} \cdot \mathrm{mm}^{-1}\right)$ [38]. Moreover, as shown in Figure 37, the HLPFG and I-HLPFG in the PCF exhibit similar high torsion sensitivities, i.e., 220.49 and 
$221.73 \mathrm{~nm} /\left(\mathrm{rad} \cdot \mathrm{mm}^{-1}\right)$ [16]. According to the experimental results, we could distinguish the applied torsion direction by observing blue- or red-shift of the resonant wavelength.
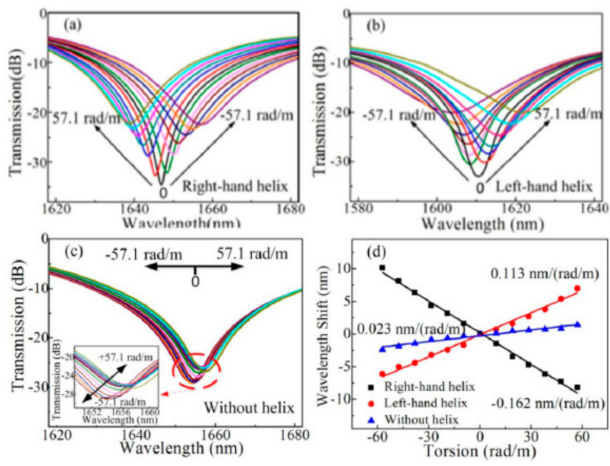

Figure 36. Resonant wavelength shifts for (a) right-hand; and (b) left-handed pre-twisted LPFG; and (c) conventional LPFG. (d) Measured resonant wavelength shift versus the applied torsion [46].
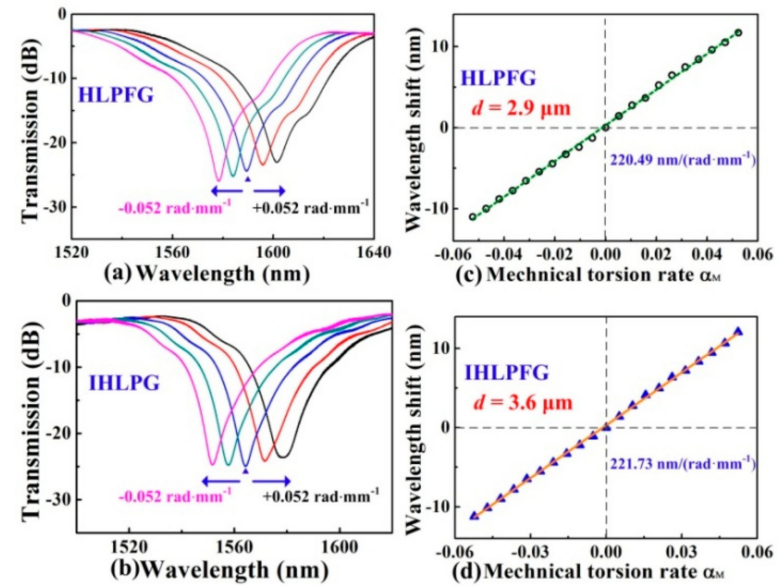

Figure 37. Transmission spectrum evolution of the (a) HLPFG and (b) I-HLPFG in PCF with air-hole diameters of 2.9 and $3.6 \mu \mathrm{m}$, respectively; measured resonant wavelength shift of the (c) HLPFG and (d) I-HLPFG as a function of the mechanical torsion [16].

In addition, a HLPFG in the multi-core fiber (MCF) fabricated by $\mathrm{CO}_{2}$ laser heating technology shows a torsion sensitivity up to $198 \mathrm{~nm} /\left(\mathrm{rad} \cdot \mathrm{mm}^{-1}\right)$ [77]. A directional torsion sensor fabricated by twisting the MCF based on the Mach-Zehnder interferometer exhibited a sensitivity of $\sim 118.0 \mathrm{~nm} /\left(\mathrm{rad} \cdot \mathrm{mm}^{-1}\right)$ while the applied torsion changed from $-17.094 \mathrm{rad} / \mathrm{m}$ to $15.669 \mathrm{rad} / \mathrm{m} \mathrm{[109]}$.

\section{Biochemical Sensors}

The resonant wavelength or attenuation peak of the SLPFG is sensitive to the surrounding refractive index due to the cladding mode coupled from the fundamental light [67]. SLPFG sensors have drawn great attention in the field of refractive index sensing owing to the label-free, high sensitivity, and real-time measurement. Moreover, specific detections could be achieved by modifying different types of functional material on the surface of the SLPFGs. SLPFGs have been utilized in chemical and biomass applications such as the detection of specific biological molecules, composition or content of a gas, and corrosion in the steel.

A chemical sensor coated with the functional material, i.e., incorporation of diphenyl siloxane and titanium cross-linker on the SLPFG, successfully realized the chemical differentiation of cyclohexane and xylene, where the detection limit is $300 \mathrm{ppm}$ for the xylene vapor [68]. A stable sensor using SLPFG has been developed for the detection of triacylglycerides, where the lipase enzyme is immobilized 
on the fiber by means of covalent binding technique, as shown in Figure 38. The sensors showed a sensitivity of $0.5 \mathrm{~nm} / \mathrm{mM}$ and a low detection limit of $17.71 \mathrm{mg} / \mathrm{dL}$ in human blood [69].

The detection of the composition or content of a gas is necessary in industry and healthcare. Hromadka et al. presented a SLPFG-based carbon dioxide $\left(\mathrm{CO}_{2}\right)$ sensor by coated with HKUST-1, i.e., a material from the metal-organic frame on the fiber. The SLPFG coated with 40 layers HKUST-1 by means of layer-by-layer techniques was sensitive to the $\mathrm{CO}_{2}$ concentration between 2000 and $40,000 \mathrm{ppm}$ with a detection limit of $401 \mathrm{ppm}$ [70]. The methane sensor was fabricated by depositing the inclusion of cryptophane A in the styrene-acrylonitrile cladding on the SLPFGs, where the sensing film is sensitive to the adsorption of methane in the surroundings. The achieved sensor based on SLPFG exhibited a good sensitivity $\left(\sim 0.375 \mathrm{~nm}^{\circ}{ }^{-1}\right)$ for the methane below $3.5 \mathrm{vol} \%$ [71].

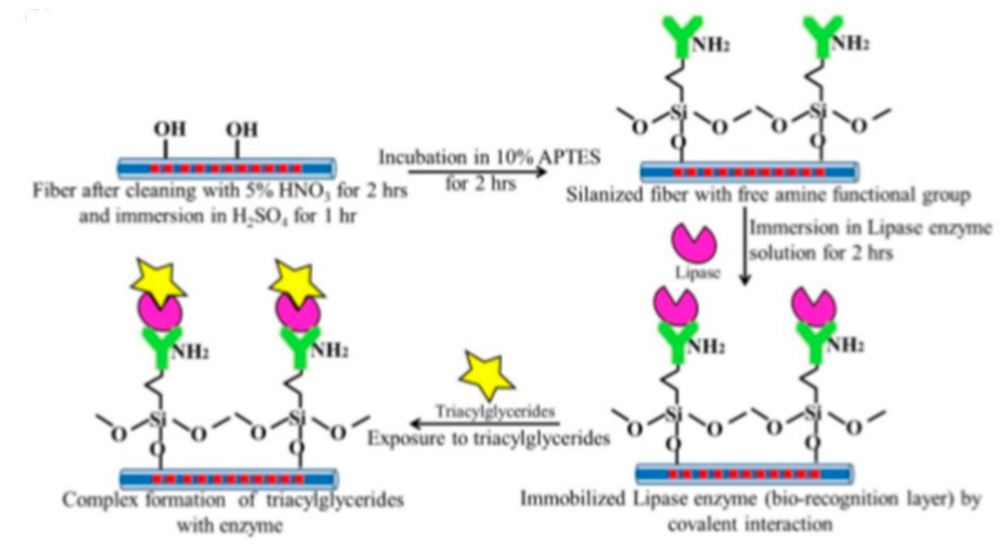

Figure 38. Schematic diagram of the layer-by-layer modification of SLPFG.

SLPFG sensor coated with a layer of polyurethane and iron/silica nanoparticles was developed to detect the corrosion process of deformed steel bars. However, the experimental results show that the corrosion sensitivity would decrease significantly with the extension of the service time [72]. Then, a sensor based on SLPFG written in SMF by a transverse focused $\mathrm{CO}_{2}$ laser was demonstrated to monitor the corrosion process of carbon steel in a $3.5 \mathrm{wt} \% \mathrm{NaCl}$ solution. The SLPFG was firstly deposited with a $\sim 0.8-\mu \mathrm{m}$-thick Ag film, and then electroplated an outer $\sim 20-\mu \mathrm{m}$-thick Fe-C film. In addition, the thickness of the $\mathrm{Ag}$ and $\mathrm{Fe}-\mathrm{C}$ strongly affected the corrosion sensitivity and the lifecycle [73].

\section{Conclusions}

In conclusion, the recent progress in fabrications and applications of heating-induced LPFGs have been reviewed in this work. High-quality SLPFGs and HLPFGs in conventional glass fibers, PCFs, and PBFs could be obtained by use of three kinds of heating fabrication techniques, i.e., $\mathrm{CO}_{2}$ laser, arc discharge, and hydrogen-oxygen flame. Compared with SLPFG, HLPFG refers to a fiber where there exists a periodical helical structure such as a screw index-modulation along the fiber axis. Then, the OAM mode convertors based on SLPFGs and HLPFGs have been described. The OAM mode convertors based on SLPFGs require external devices, e.g., rotators, polarizers, polarization controllers, or piezo delay stages, to adjust the phase difference or polarization direction; while the HLPFGs could directly generate the OAM modes due to their helical structure. Heating-induced LPFGs have found promising sensing applications, such as strain, pressure, torsion, and biochemical sensors. The HLPFGs could distinguish the torsion direction by observing the red-shift or blue-shift of the resonant wavelength.

Author Contributions: C.F. and Y.W. conceived and wrote the review. S.L., Z.B., C.L., J.H., and Y.W. helped to polish the fiber. All authors read and approved this manuscript. 
Funding: This work is supported by the National Natural Science Foundation of China (NSFC) (61425007, 61635007); Science and Technology Innovation Commission of Shenzhen (JCYJ20170412105604705); Development and Reform Commission of Shenzhen Municipality Foundation.

Conflicts of Interest: The author declares no conflict of interest.

\section{References}

1. Hill, K.; Fujii, Y.; Johnson, D. Photosensitivity in optical fiber waveguides-application to reflection filter fabrication. Appl. Phys. Lett. 1978, 32, 647-649. [CrossRef]

2. Rao, Y. In-fibre Bragg grating sensors. Meas. Sci. Technol. 1997, 8, 355-375. [CrossRef]

3. Rao, Y. Recent progress in applications of in-fibre Bragg grating sensors. Opt. Lasers Eng. 1999, 31, $297-324$. [CrossRef]

4. Gagne, M.; Loranger, S.; Lapointe, J.; Kashyap, R. Fabrication of high quality, ultra-long fiber Bragg gratings: Up to 2 million periods in phase. Opt. Express 2014, 22, 387-398. [CrossRef]

5. Bhatia, V.; Vengsarkar, A. Optical fiber long-period grating sensors. Opt. Lett. 1996, 21, 692-694. [CrossRef]

6. Davis, D.; Gaylord, T.; Glytsis, E.; Kosinski, S.; Mettler, S.; Vengsarkar, A. Long-period fibre grating fabrication with focused $\mathrm{CO}_{2}$ laser pulses. Electron. Lett. 1998, 34, 302-303. [CrossRef]

7. Davis, D.; Gaylord, T.; Glytsis, E.; Mettler, S. $\mathrm{CO}_{2}$ laser-induced long-period fibre gratings: Spectral characteristics, cladding modes and polarisation independence. Electron. Lett. 1998, 34, 1416-1417. [CrossRef]

8. Vengsarkar, A.; Lemaire, P.; Judkins, J.; Bhatia, V.; Erdogan, T.; Sipe, J. Long-period fiber gratings as band-rejection filters. J. Lightware Technol. 1996, 14, 58-65. [CrossRef]

9. Kopp, V.; Churikov, V.; Singer, J.; Chao, N.; Neugroschl, D.; Genack, A. Chiral fiber gratings. Science 2004, 305, 74-75. [CrossRef]

10. Oh, S.; Lee, K.; Paek, U.; Chung, Y. Fabrication of helical long-period fiber gratings by use of a $\mathrm{CO}_{2}$ laser. Opt. Lett. 2004, 29, 1464-1466. [CrossRef]

11. Wang, P.; Li, H. Helical long-period grating formed in a thinned fiber and its application to a refractometric sensor. Appl. Opt. 2016, 55, 1430-1434. [CrossRef] [PubMed]

12. Kong, X.; Ren, K.; Ren, L.; Liang, J.; Ju, H. Chiral long-period gratings: Fabrication, highly sensitive torsion sensing, and tunable single-band filtering. Appl. Opt. 2017, 56, 4702-4707. [CrossRef] [PubMed]

13. Fu, C.; Liu, S.; Bai, Z.; He, J.; Liao, C.; Wang, Y.; Li, Z.; Zhang, Y.; Yang, K.; Yu, B.; et al. Orbital angular momentum mode converter based on helical long period fiber Grating Inscribed by Hydrogen-Oxygen Flame. J. Lightware Technol. 2018, 36, 1683-1688. [CrossRef]

14. Fu, C.; Liu, S.; Wang, Y.; Bai, Z.; He, J.; Liao, C.; Zhang, Y.; Zhang, F. High-order orbital angular momentum mode generator based on twisted photonic crystal fiber. Opt. Lett. 2018, 43, 1786-1789. [CrossRef] [PubMed]

15. Fu, C.; Wang, Y.; Bai, Z.; Liu, S. Twist-direction-dependent orbital angular momentum generator based on inflation-assisted helical photonic crystal fiber. Opt. Lett. 2019, 44, 459-462. [CrossRef] [PubMed]

16. Fu, C.; Wang, Y.; Liu, S.; Bai, Z.; Tang, J.; Shao, L.; Liu, X. Transverse-load, strain, temperature, and torsion sensors based on a helical photonic crystal fiber. Opt. Lett. 2019, 44, 1984-1987. [CrossRef]

17. Zhang, Y.; Bai, Z.; Fu, C.; Liu, S.; Tang, J.; Yu, J.; Liao, C.; Wang, Y.; He, J. Polarization-independent orbital angular momentum generator based on a chiral fiber grating. Opt. Lett. 2019, 44, 61-64. [CrossRef]

18. Wong, G.; Kang, M.; Lee, H.; Biancalana, F.; Conti, C.; Weiss, T. Excitation of orbital angular momentum resonances in helically twisted photonic crystal fiber. Science 2012, 337, 446-449. [CrossRef]

19. Xi, X.; Wong, G.; Thomas, W.; Russell, P. Measuring mechanical strain and twist using helical photonic crystal fiber. Opt. Lett. 2013, 38, 5401. [CrossRef]

20. Xi, X.; Wong, G.; Frosz, M.; Babic, F.; Ahmed, G.; Jiang, X. Orbital-angular-momentum-preserving helical Bloch modes in twisted photonic crystal fiber. Optica 2014, 1, 165-169. [CrossRef]

21. Xi, X.; Weiss, T.; Wong, G.; Biancalana, F.; Barnett, S.; Padgett, M.; Russell, P. Optical activity in twisted solid-core photonic crystal fibers. Phys. Rev. Lett. 2013, 110, 143903. [CrossRef] [PubMed]

22. Li, Z.; Liu, S.; Bai, Z.; Fu, C.; Zhang, Y.; Sun, Z.; Liu, X.; Wang, Y. Residual-stress-induced helical long period fiber gratings for sensing applications. Opt. Express 2018, 26, 24113-24122. [CrossRef] [PubMed]

23. Rao, Y.; Wang, Y.; Ran, Z.; Zhu, T. Novel fiber-optic sensors based on long-period fiber gratings written by high-frequency $\mathrm{CO}_{2}$ laser pulses. J. Lightwave Technol. 2003, 21, 1320-1327. 
24. Rao, Y.; Zhu, T.; Ran, Z.; Wang, Y.; Jiang, J.; Hu, A. Novel long-period fiber gratings written by high-frequency $\mathrm{CO}_{2}$ laser pulses and applications in optical fiber communication. Opt. Commun. 2004, 229, $209-221$. [CrossRef]

25. Wang, Y.; Wang, D.; Jin, W.; Rao, Y.; Peng, G. Asymmetric long period fiber gratings fabricated by use of $\mathrm{CO}_{2}$ laser to carve periodic grooves on the optical fiber. Appl. Phys. Lett. 2006, 89, 151105. [CrossRef]

26. Tian, F.; Kanka, J.; Zou, B.; Chiang, K.; Du, H. Long-period gratings inscribed in photonic crystal fiber by symmetric $\mathrm{CO}_{2}$ laser irradiation. Opt. Express 2013, 21, 13208-13218. [CrossRef]

27. Wang, Y.; Jin, W.; Ju, J.; Xuan, H.; Ho, H.; Xiao, L.; Wang, D. Long period gratings in air-core photonic bandgap fibers. Opt. Express 2008, 16, 2784-2790. [CrossRef]

28. Zhong, X.; Wang, Y.; Liao, C.; Yin, G.; Zhou, J.; Wang, G.; Sun, B. Long period fiber gratings inscribed with an improved two-dimensional scanning technique. IEEE Photon. J. 2014, 6, 1-8. [CrossRef]

29. Zhong, X.; Wang, Y.; Liao, C.; Liu, S.; Tang, J. Temperature-insensitivity gas pressure sensor based on inflated long period fiber grating inscribed in photonic crystal fiber. Opt. Lett. 2015, 40, 1791-1794. [CrossRef]

30. Tang, J.; Yin, G.; Liu, S.; Zhong, X.; Liao, C.; Li, Z. Gas pressure sensor based on $\mathrm{CO}_{2}$-laser-induced long-period fiber grating in air-core photonic bandgap fiber. IEEE Photon. J. 2015, 7, 1-7.

31. Tang, J.; Zhang, Z.; Yin, G.; Liu, S.; Bai, Z.; Li, Z.; Deng, M. Long period fiber grating inscribed in hollow-core photonic bandgap fiber for gas pressure sensing. IEEE Photon. J. 2017, 9, 1-7. [CrossRef]

32. Fu, C.; Zhong, X.; Liao, C.; Wang, Y.; Wang, Y.; Tang, J.; Liu, S. Thin-core-fiber-based long-period fiber grating for high-sensitivity refractive index measurement. IEEE Photon. J. 2015, 7, 1-8. [CrossRef]

33. Humbert, G.; Malki, A.; Fevrier, S.; Roy, P. Electric arc-induced long-period gratings in Ge-free air-silica microstructure fibres. Electron. Lett. 2003, 39, 349-350. [CrossRef]

34. Rego, G.; Santos, J.; Salgado, H. Polarization dependent loss of arc-induced long-period fibre gratings. Opt. Commun. 2006, 262, 152-156. [CrossRef]

35. Yin, G.; Wang, Y.; Liao, C.; Zhou, J.; Zhong, X.; Wang, G.; Sun, B.; He, J. Long period fiber gratings inscribed by periodically tapering a fiber. IEEE Photon. Technol. Lett. 2014, 26, 698-701. [CrossRef]

36. Yin, G.; Tang, J.; Liao, C.; Wang, Y. Automatic arc discharge technology for inscribing long period fiber gratings. Appl. Opt. 2016, 55, 3873-3878. [CrossRef]

37. Sun, B.; Wei, W.; Liao, C.; Zhang, L. Automatic arc discharge-induced helical long period fiber gratings and its sensing applications. IEEE Photon. Technol. Lett. 2017, 29, 873-876. [CrossRef]

38. Li, J.; Fan, P.; Sun, L.; Wu, C.; Guan, B. Few-period helically twisted all-solid photonic bandgap fibers. Opt. Lett. 2018, 43, 655-658. [CrossRef]

39. Kondo, Y.; Nouchi, K.; Mitsuyu, T.; Watanabe, M. Fabrication of long-period fiber gratings by focused irradiation of infrared femtosecond laser pulses. Opt. Lett. 1999, 24, 646-648. [CrossRef]

40. Tang, J.; Fu, C.; Bai, Z.; Liao, C.; Wang, Y. Sensing characteristics of tilted long period fiber gratings inscribed by infrared femtosecond laser. Sensors 2018, 18, 3003. [CrossRef]

41. Zhou, X.; Shi, S.; Zhang, Z.; Zou, J.; Liu, Y. Mechanically-induced pi-shifted long-period fiber gratings. Opt. Express 2011, 19, 6253-6259. [CrossRef] [PubMed]

42. Nair, A.; Kumar, V.; Joe, H. Widely tunable $\mathrm{LP}_{11}$ cladding-mode resonance in a twisted mechanically induced long-period fiber grating. Appl. Opt. 2015, 54, 2007-2010. [CrossRef] [PubMed]

43. Lin, C.; Wang, Y. Loss-tunable long period fibre grating made from etched corrugation structure. Electron. Lett. 1999, 35, 1872-1873. [CrossRef]

44. Chiang, C.; Tsai, L. Perfectly notched long-period fiber grating filter based on ICP dry etching technique. Opt. Lett. 2012, 37, 193-195. [CrossRef] [PubMed]

45. Fujimaki, M.; Ohki, Y.; Brebner, J.; Roorda, S. Fabrication of long-period optical fiber gratings by use of ion implantation. Opt. Lett. 2000, 25, 88-89. [CrossRef] [PubMed]

46. Deng, M.; Xu, J.; Zhang, Z.; Bai, Z.; Liu, S.; Wang, Y.; Zhang, Y. Long period fiber grating based on periodically screw-type distortions for torsion sensing. Opt. Express 2017, 25, 14308-14316. [CrossRef]

47. Li, Y.; Lu, P.; Zhang, C.; Ni, W.; Liu, D. Sensing characterization of helical long period fiber grating fabricated by a double-side $\mathrm{CO}_{2}$ Laser in single-mode fiber. IEEE Photon. J. 2019, 11, 1-8. [CrossRef]

48. Zhong, X.; Wang, Y.; Qu, J.; Liao, C.; Liu, S.; Tang, J.; Wang, Q.; Zhao, J. High-sensitivity strain sensor based on inflated long period fiber grating. Opt. Lett. 2014, 39, 5463-5466. [CrossRef]

49. Liu, S.; Zhang, Y.; Fu, C.; Bai, Z. Temperature insensitivity polarization-controlled orbital angular momentum mode converter based on an LPFG induced in four-mode fiber. Sensors 2018, 18, 1766. [CrossRef] 
50. Bai, Z.; Li, M.; Wang, Y.; Tang, J.; Zhang, Z.; Liu, S.; Fu, C.; Zhang, Y. Orbital angular momentum generator based on hollow-core photonic bandgap fiber grating. Appl. Phys. Express 2019, 12, 072004. [CrossRef]

51. Li, S.; Mo, Q.; Hu, X.; Du, C.; Wang, J. Controllable all-fiber orbital angular momentum mode converter. Opt. Lett. 2015, 40, 4376-4379. [CrossRef] [PubMed]

52. Zhao, Y.; Liu, Y.; Zhang, L.; Zhang, C.; Wen, J.; Wang, T. Mode converter based on the long-period fiber gratings written in the two-mode fiber. Opt. Express 2016, 24, 6186-6195. [CrossRef] [PubMed]

53. Zhao, Y.; Liu, Y.; Zhang, C.; Zhang, L.; Zheng, G.; Mou, C.; Wen, J. All-fiber mode converter based on long-period fiber gratings written in few-mode fiber. Opt. Lett. 2017, 42, 4708-4711. [CrossRef] [PubMed]

54. Wu, H.; Gao, S.; Huang, B.; Feng, Y.; Huang, X. All-fiber second-order optical vortex generation based on strong modulated long-period grating in a four-mode fiber. Opt. Lett. 2017, 42, 5210-5213. [CrossRef]

55. Zhang, W.; Wei, K.; Huang, L.; Mao, D.; Jiang, B.; Gao, F. Optical vortex generation with wavelength tunability based on an acoustically-induced fiber grating. Opt. Express 2016, 24, 19278-19285. [CrossRef]

56. Zhang, W.; Huang, L.; Wei, K.; Li, P.; Jiang, B. High-order optical vortex generation in a few-mode fiber via cascaded acoustically driven vector mode conversion. Opt. Lett. 2016, 41, 5082-5085. [CrossRef]

57. Wang, Y.; Xiao, L.; Wang, D.; Jin, W. Highly sensitive long-period fiber-grating strain sensor with low temperature sensitivity. Opt. Lett. 2006, 31, 3414-3416. [CrossRef]

58. Jung, H.; Shin, W.; Kim, J.; Park, S.; Ko, D.; Lee, J. Bending and strain sensitivities in a helicoidal long-period fiber gratings. IEEE Photon. Technol. Lett. 2009, 21, 1232-1234. [CrossRef]

59. Subramanian, R.; Zhu, C.; Zhao, H.; Li, H. Torsion, Strain, and temperature sensor based on helical long-period fiber gratings. IEEE Photon. Technol. Lett. 2018, 30, 327-330. [CrossRef]

60. Zhang, H.; Wu, Z.; Shum, P.; Low, C.; Xu, Z.; Wang, R.; Shao, X. Highly sensitive strain sensor based on helical structure combined with Mach-Zehnder interferometer in multicore fiber. Sci. Rep. 2017, 7, 46633. [CrossRef]

61. Zhu, T.; Rao, Y.; Song, Y. High-sensitivity temperature-independent strain sensor based on a long-period fiber grating with a $\mathrm{CO}_{2}$-laser engraved rotary structure. IEEE Photon. Technol. Lett. 2009, 21, 543-545.

62. Wang, P.; Li, H. Fabrication of phase-shifted long-period fiber grating and its application to strain measurement. IEEE Photon. Technol. Lett. 2015, 27, 557-560. [CrossRef]

63. Ren, K.; Ren, L.; Liang, J.; Kong, X.; Ju, H.; Wu, Z. Highly strain and bending sensitive microtapered long-period fiber gratings. IEEE Photon. Technol. Lett. 2017, 29, 1085-1088. [CrossRef]

64. Jin, X.; Sun, C.; Duan, S.; Liu, W.; Yuan, L. High strain sensitivity temperature sensor based on a secondary modulated tapered long Period Fiber Grating. IEEE Photon. J. 2019, 11, 1-8. [CrossRef]

65. Bock, W.; Chen, J.; Mikulic, P.; Eftimov, T. A novel fiber-optic tapered long-period grating sensor for pressure monitoring. IEEE Trans. Instrum. Meas. 2007, 56, 1176-1180. [CrossRef]

66. Bock, W.; Chen, J.; Mikulic, P.; Eftimov, T. Pressure sensing using periodically tapered long-period gratings written in photonic crystal fibres. Meas. Sci. Technol. 2007, 18, 3098. [CrossRef]

67. Vaiano, P.; Carotenuto, B.; Pisco, M.; Ricciardi, A.; Quero, G. Lab on fiber technology for biological sensing applications. Laser Photon. Rev. 2016, 10, 922-961. [CrossRef]

68. Barnes, J.; Dreher, M.; Plett, K.R.; Brown, R.; Crudden, C. Chemical sensor based on a long-period fibre grating modified by a functionalized polydimethylsiloxane coating. Analyst 2008, 133, 1541-1549. [CrossRef]

69. Baliyan, A.; Sital, S.; Tiwari, U.; Gupta, R.; Sharma, E. Long period fiber grating based sensor for the detection of triacylglycerides. Biosens. Bioelectron. 2016, 79, 693-700. [CrossRef]

70. Hromadka, J.; Tokay, B.; Correia, R.; Morgan, S.; Korposh, S. Carbon dioxide measurements using long period grating optical fibre sensor coated with metal organic framework HKUST-1. Sens. Actuator B Chem. 2018, 255, 2483-2494. [CrossRef]

71. Yang, J.; Tao, C.; Li, X. Long-period fiber grating sensor with a styrene-acrylonitrile nano-film incorporating cryptophane A for methane detection. Opt. Express 2011, 19, 14696-14706. [CrossRef] [PubMed]

72. Huang, Y.; Tang, F.; Liang, X.; Chen, G.; Xiao, H.; Azarmi, F. Steel bar corrosion monitoring with long-period fiber grating sensors coated with nano iron/silica particles and polyurethane. Struct. Health Monit. 2015, 14, 178-189. [CrossRef]

73. Chen, Y.; Tang, F.; Bao, Y.; Tang, Y.; Chen, G. A Fe-C coated long-period fiber grating sensor for corrosion-induced mass loss measurement. Opt. Lett. 2016, 41, 2306-2309. [CrossRef] [PubMed]

74. Wang, Y. Review of long period fiber gratings written by $\mathrm{CO}_{2}$ laser. J. Appl. Phys. 2010, 108, 11. [CrossRef] 
75. Inoue, G.; Li, H.; Wang, P. Flat-top band-rejection filter based on two successively-cascaded helical fiber gratings. Opt. Express 2016, 24, 5442. [CrossRef]

76. Zhang, L.; Liu, Y.; Zhao, Y.; Wang, T. High sensitivity twist sensor based on helical long-period grating written in two-mode fiber. IEEE Photon. Technol. Lett. 2016, 28, 1629-1632. [CrossRef]

77. Shen, X.; Hu, X.; Yang, L.; Dai, N.; Wu, J.; Zhang, F.; Peng, J.; Li, H. Helical long-period grating manufactured with a $\mathrm{CO}_{2}$ laser on multicore fiber. Opt. Express 2017, 25, 10405-10412.

78. Jiang, C.; Liu, Y.; Zhao, Y.; Mou, C.; Wang, T. Helical long-period gratings inscribed in polarization-maintaining fibers by $\mathrm{CO}_{2}$ laser. J. Lightwave Technol. 2019, 37, 889-896. [CrossRef]

79. Shin, W.; Yu, B.; Noh, Y.; Lee, J.; Ko, D.; Oh, K. Bandwidth-tunable band-rejection filter based on helicoidal fiber grating pair of opposite helicities. Opt. Lett. 2007, 32, 1214-1216. [CrossRef]

80. Eggleton, B.; Westbrook, P.; White, C.; Kerbage, C.; Windeler, R. Cladding-mode-resonances in air-silica microstructure optical fibers. J. Lightwave Technol. 2000, 18, 1084-1100. [CrossRef]

81. Luo, M.; Qiang, J.; Liu, S. Sensing Characteristics of femtosecond laser-induced long period gratings by filling cladding holes in photonic crystal fiber. J. Lightwave Technol. 2014, 32, 2287-2292.

82. Kakarantzas, G.; Birks, T.; Russell, P. Structural long-period gratings in photonic crystal fibers. Opt. Lett. 2002, 27, 1013-1015. [CrossRef] [PubMed]

83. Zhu, Y.; Shum, P.; Chong, J.; Rao, M.; Lu, C. Deep-notch, ultracompact long-period grating in a large-mode-area photonic crystal fiber. Opt. Lett. 2003, 28, 2467-2469. [CrossRef] [PubMed]

84. Zhu, Y.; Shum, P.; Bay, H.; Yan, M.; Yu, X.; Hu, J.; Hao, J.; Lu, C. Strain-insensitive and high-temperature long-period gratings inscribed in photonic crystal fiber. Opt. Lett. 2005, 30, 367-369. [CrossRef]

85. Lee, H.; Liu, Y.; Chiang, K. Writing of long-period gratings in conventional and photonic-crystal polarization-maintaining fibers by $\mathrm{CO}_{2}$-laser pulses. IEEE Photon. Technol. Lett. 2008, 20, 132-134. [CrossRef]

86. Ivanov, O. Fabrication of long-period fiber gratings by twisting a standard single-mode fiber. Opt. Lett. 2005, 30, 3290-3292. [CrossRef]

87. Russell, P.; Beravat, R.; Wong, G. Helically twisted photonic crystal fibres. Philos. Trans. R. Soc. A Math. Phys. Eng. Sci. 2017, 375, 20150440. [CrossRef]

88. Ma, X.; Liu, C.; Chang, G.; Galvanauskas, A. Angular-momentum coupled optical waves in chirally-coupled-core fibers. Opt. Express 2011, 19, 26515-26528. [CrossRef]

89. Beravat, R.; Wong, G.; Xi, X.; Frosz, M. Current sensing using circularly birefringent twisted solid-core photonic crystal fiber. Opt. Lett. 2016, 41, 1672-1675. [CrossRef]

90. Tai, B.; Wang, Z.; Liu, Y.; Xu, J.; Liu, B.; Wei, H. High order resonances between core mode and cladding supermodes in long period fiber gratings inscribed in photonic bandgap fibers. Opt. Express 2010, 18, 15361-15370. [CrossRef]

91. Poletti, F.; Petrovich, M.; Richardson, D. Hollow-core photonic bandgap fibers: technology and applications. Nanophotonics 2013, 2, 315-340. [CrossRef]

92. Rego, G.; Okhotnikov, O.; Dianov, E.; Sulimov, V. High-temperature stability of long-period fiber gratings produced using an electric arc. J. Lightwave Technol. 2001, 19, 1574-1579. [CrossRef]

93. Ivanov, O.; Rego, G. Origin of coupling to antisymmetric modes in arc-induced long-period fiber gratings. Opt. Express 2007, 15, 13936-13941. [CrossRef] [PubMed]

94. Esposito, F.; Ranjan, R.; Campopiano, S.; Iadicicco, A. Arc-induced long period gratings from standard to polarization-maintaining and photonic crystal fibers. Sensors 2018, 18, 918. [CrossRef] [PubMed]

95. Iaducucco, A.; Campopiano, S.; Cusano, A. Long-Period gratings in hollow core Fibers by pressure-assisted arc discharge technique. IEEE Photon. Technol. Lett. 2011, 23, 1567-1569. [CrossRef]

96. Iaducucco, A.; Ranjan, R.; Esposito, F.; Campopiano, S. Arc-Induced Long Period Gratings in Polarization-Maintaining Panda Fiber. IEEE Photon. Technol. Lett. 2017, 29, 1533-1536.

97. Gregg, P.; Kristensen, P.; Ramachandran, S. Conservation of orbital angular momentum in air-core optical fibers. Optica 2015, 2, 267-270. [CrossRef]

98. Padgett, M.; Allen, L. Orbital angular momentum exchange in cylindrical-lens mode converters. J. Opt. B Quantum Semiclassical Opt. 2002, 4, S17-S19. [CrossRef]

99. Cai, X.; Wang, J.; Strain, M.; Johnsonmorris, B.; Zhu, J.; Sorel, M.; Brien, J.; Thompson, M.; Yu, S. Integrated Compact Optical Vortex Beam Emitters. Science 2012, 338, 363-366. [CrossRef] 
100. Zhao, Z.; Wang, J.; Li, S.; Willner, A. Metamaterials-based broadband generation of orbital angular momentum carrying vector beams. Opt. Lett. 2013, 38, 932-934. [CrossRef]

101. Wang, L.; Lin, C.; Chern, G. A torsion sensor made of a corrugated long period fibre grating. Meas. Sci. Technol. 2001, 12, 793. [CrossRef]

102. Kim, H.; Kim, T.; Kim, B.; Chung, Y. Temperature-insensitive torsion sensor with enhanced sensitivity by use of a highly birefringent photonic crystal fiber. IEEE Photon. Technol. Lett. 2010, 22, 1539-1541. [CrossRef]

103. Yan, Z.; Mou, C.; Zhou, K.; Chen, X.; Zhang, L. UV-Inscription, Polarization-dependant loss characteristics and applications of $45^{\circ}$ tilted fiber gratings. J. Lightwave Technol. 2011, 29, 2715-2724. [CrossRef]

104. Yang, F.; Fang, Z.; Pan, Z.; Ye, Q.; Cai, H.; Qu, R. Orthogonal polarization mode coupling for pure twisted polarization maintaining fiber Bragg gratings. Opt. Express 2012, 20, 28839-28845. [CrossRef] [PubMed]

105. Zu, P.; Chan, C.; Jin, Y. A Temperature-insensitive twist sensor by using low-birefringence photonic-crystal-fiber-based sagnac interferometer. IEEE Photon. Technol. Lett. 2011, 23, 920-922. [CrossRef]

106. Wo, J.; Jiang, M.; Mainou, M.; Sun, Q.; Zhang, J. Twist sensor based on axial strain insensitive distributed Bragg reflector fiber laser. Opt. Express 2012, 20, 2844-2850. [CrossRef]

107. Wang, Y.; Rao, Y. Long period fibre grating torsion sensor measuring twist rate and determining twist direction simultaneously. Electron. Lett. 2004, 40, 164-166. [CrossRef]

108. Wang, Y.; Chen, J.; Rao, Y. Torsion characteristics of long-period fiber gratings induced by high-frequency $\mathrm{CO}_{2}$ laser pulses. J. Opt. Soc. Am. B Opt. Phys. 2005, 22, 1167-1172. [CrossRef]

109. Zhang, H.; Wu, Z.; Shum, P.; Shao, X.; Wang, R.; Dinh, X.; Fu, S.; Tong, W.; Tang, M. Directional torsion and temperature discrimination based on a multicore fiber with a helical structure. Opt. Express 2018, 26, 544-551. [CrossRef]

(C) 2019 by the authors. Licensee MDPI, Basel, Switzerland. This article is an open access article distributed under the terms and conditions of the Creative Commons Attribution (CC BY) license (http://creativecommons.org/licenses/by/4.0/). 